\title{
The Role of Disulfide Bond Replacements in Analogues of the Tarantula Toxin ProTx-II and Their Effects on Inhibition of the Voltage-Gated Sodium Ion Channel $\mathrm{Na}_{\mathrm{v}} 1.7$
}

Zoë V. F. Wright, ${ }^{\dagger}$ Stephen McCarthy, ${ }^{\dagger}$ Rachael Dickman, ${ }^{\dagger}$ Francis E. Reyes, ${ }^{*}$ Silvia Sanchez-Martinez, ${ }^{\#}$ Adam Cryar, ${ }^{\ddagger}$ Ian Kilford, ${ }^{\S}$ Adrian Hall, ${ }^{\S}$ Andrew K. Takle, ${ }^{\S}$ Maya Topf, ${ }^{\perp}$ Tamir Gonen,, Konstantinos Thalassinos, ${ }^{*}+\perp$ and Alethea B. Tabor ${ }^{*}, \dagger$

${ }^{\dagger}$ Department of Chemistry, University College London, 20 Gordon Street, London WC1H 0AJ, United Kingdom

\#Janelia Research Campus, Howard Hughes Medical Institute, Ashburn, Virginia 20147, United States

${ }^{\ddagger}$ Institute of Structural and Molecular Biology, Division of Biosciences, University College London, Gower Street, London WC1E 6BT, United Kingdom

${ }^{\perp}$ Institute of Structural and Molecular Biology, Department of Biological Sciences, Birkbeck College, University of London, London WC1E 7HX, United Kingdom

${ }^{\S}$ European Knowledge Centre, Eisai Limited, Mosquito Way, Hatfield, Hertfordshire AL10 9SN, United Kingdom

\section{Supporting Information}

ABSTRACT: Spider venom toxins, such as Protoxin-II (ProTx-II), have recently received much attention as selective $\mathrm{Na}_{\mathrm{v}} 1.7$ channel blockers, with potential to be developed as leads for the treatment of chronic nocioceptive pain. ProTx-II is a 30 -amino acid peptide with three disulfide bonds that has been reported to adopt a well-defined inhibitory cystine knot (ICK) scaffold structure. Potential drawbacks with such peptides include poor pharmacodynamics and potential scrambling of the disulfide bonds in vivo. In order to address these issues, in the present study we report the solid-phase synthesis of lanthionine-bridged analogues of ProTx-II, in which one of the three disulfide bridges is replaced with a thioether linkage, and evaluate the biological properties of

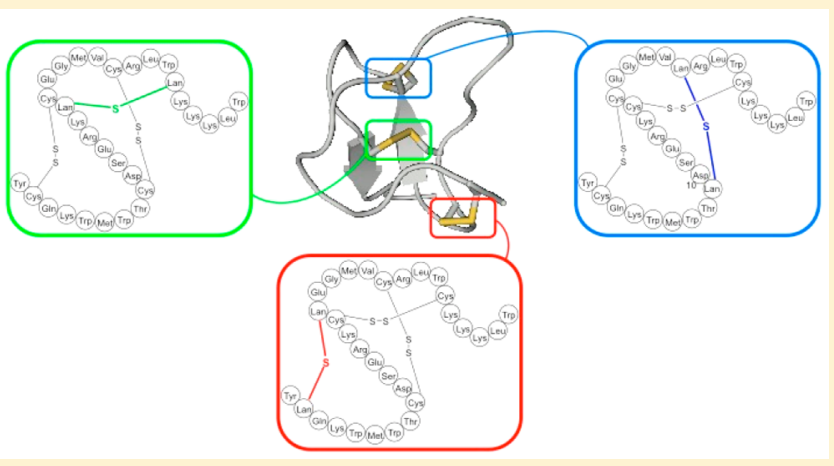
these analogues. We have also investigated the folding and disulfide bridging patterns arising from different methods of oxidation of the linear peptide precursor. Finally, we report the X-ray crystal structure of ProTx-II to atomic resolution; to our knowledge this is the first crystal structure of an ICK spider venom peptide not bound to a substrate.

\section{INTRODUCTION}

Peptide toxins hold considerable promise as novel therapeutics due to the potency and specificity with which they interact with their biological targets, low cost of synthesis, and largely wellunderstood metabolic pathways. ${ }^{1}$ These peptides are often cysteine-rich and contain intricate disulfide bonding patterns that are crucial for their biological activity. ${ }^{2}$ Despite these encouraging properties, however, to date only one peptide toxin-based therapeutic (Ziconitide, marketed as Prialt) has been approved for clinical use. ${ }^{3}$ This is largely due to commonly encountered problems in the in vivo stability of peptide toxins. Poor transport across the intestinal wall and susceptibility to enzymatic degradation mean that peptide toxins are not often suitable for oral administration and must be administered by intrathecal injection. ${ }^{3}$ Poor pharmacodynamics profiles are also an issue: none of these peptide toxins can cross the blood-brain or blood-nerve barriers easily. ${ }^{4}$ In addition, many toxins still show a lack of receptor subtype selectivity, leading to undesired side effects. ${ }^{5}$ Finally, the disulfide bonds in these toxins are susceptible to reduction in extracellular environments, by glutathione and disulfide bond isomerases, leading to chain unfolding and oxidative refolding with consequent loss of biological activity. ${ }^{6}$ Considerable efforts have therefore been directed toward developing replacements for the disulfide bonds in peptide toxins that are not susceptible to reduction or oxidative refolding. One of the earliest methods employed was the use of diselenide bonds, which have only slight steric differences to the native disulfide bond. ${ }^{6}$ Further studies showed that the diselenide analogues did not undergo reduction in blood plasma and actually showed slightly improved potency over the native structure. ${ }^{7}$ Both unsaturated $^{8,9}$ and saturated ${ }^{10}$ dicarba-bridges have also been used as disulfide bond replacements in cystine-rich toxins, using either

Received: June 22, 2017

Published: September 7, 2017 
ring-closing metathesis ${ }^{8,9,11}$ or solid-phase peptide synthesis (SPPS) using differentially protected diamino diacids ${ }^{10}$ as the synthetic strategy. These disulfide bond replacements resulted in peptide toxin analogues of comparable potency, ${ }^{8}$ and in some cases replacing different cystine bridges can enable the resulting toxin analogue to be tuned to one or other of two possible receptor targets. ${ }^{9}$ Lactam bridges ${ }^{12}$ and cystathione analogues ${ }^{13}$ have also been employed to stabilize the structure and modulate the activity of peptide toxins with multiple cystine bridges, with varying impact on receptor antagonism depending on the geometry of the replacement and which of the disulfide linkages has been replaced. Carba-, ${ }^{14,15}$ cystathionine-, ${ }^{16}$ and triazole-bridged ${ }^{17}$ analogues of other disulfidebridged biologically active peptides have also been synthesized, again with varying effects on the biological properties of these peptide analogues. Surprisingly, lanthionine-bridged analogues of peptide toxins have not previously been studied. Replacement of cystine by lanthionine results in a thioether side-chain bridge that cannot be cleaved in vivo. This linkage is one bond shorter than a cystine-bridged peptide and will have different conformational preferences. However, replacement of cystine with lanthionine has been carried out with other bioactive peptides such as enkephalin ${ }^{18}$ and sandostatin ${ }^{19}$ and has led to potent analogues of these peptides, as has replacement of cystine with selenolanthionine in oxytocin analogues. $^{20}$

In previous work, we have developed solid-phase methods for synthesizing lanthionine-containing peptides, using orthogonally protected lanthionine, ${ }^{21}$ which have enabled the synthesis of a range of lantibiotics and analogues, ${ }^{22,23}$ including Lactocin $\mathrm{S}^{24}$ and Lacticin $3147 .^{25}$ Looking to extend our methodology for incorporating lanthionine bridges into peptides, we elected to attempt to synthesize lanthioninecontaining analogues of ProTx-II, a peptide isolated from the venom of the Peruvian green velvet tarantula (Thrixopelma puriens). ${ }^{26}$ ProTx-II belongs to a family of spider peptide toxins that contain six cysteine residues. These are oxidized to form three interlinked disulfide bonds, connected together in a 1-4, 2-5, and 3-6 pattern referred to as the inhibitory cystine knot (ICK) scaffold. Other examples of toxins sharing the same pattern include HwTx-IV, ${ }^{27}$ GpTx-I, ${ }^{28}$ and CcoTx-I ${ }^{29}$ (Figure $1)$. The ICK scaffold has at its core an antiparallel beta-sheet comprising two or three strands, with a third disulfide bridge inserted between the loop formed by the first two disulfide

\begin{tabular}{|c|c|}
\hline YCQKWMWTCDSERKCCEGMVCRLWCKKKLW & ProTx-II \\
\hline ECLEIFKACNPSNDQCCKSSKLVCSSRKTRWCKYQI-NH & HwTX-IV \\
\hline TCQKWMKTCDSARKCCEGLVCRLWCKKII & PaTX-I \\
\hline DCLGFMRKCIPDNDKCCRPNLVCSRTHKWCKYVF-NH & GpTx-I \\
\hline DCLGMFKSCDPENDKCCKRLVCSRSHRWCKWKL-NH & CcoTx-1 \\
\hline CKGKGAKCSRLMYDCCTGSCRSGKC-NH & Prialt \\
\hline
\end{tabular}

Figure 1. Amino acid sequences and disulfide bond connectivities of the ICK scaffold peptides ProTx-II, HwTx-IV, PaTx-1, GpTx-I, CcoTx-I, and Prialt. bridges. The number and sequence of amino acids between the cysteine residues are highly variable in these ICK peptides, leading to a wide variety of secondary structural motifs and peptide sequences being displayed between each disulfide bridge. $^{30,31}$ Effective synthetic routes to ICK peptides with disulfide bond replacements are therefore of considerable interest in the development of peptide toxins with in vivo stability and have the potential to fine-tune receptor selectivity.

ProTx-II has been the subject of particular interest from researchers as a possible lead for the treatment of chronic nociceptive pain. ${ }^{4}$ It has been reported to have both the highest potency against the voltage-gated ion channel $\mathrm{Na}_{\mathrm{v}} 1.7\left(\mathrm{IC}_{50} 0.3\right.$ $\mathrm{nM}$ ) and exceptional receptor subtype selectivity (100-fold more selective for the $\mathrm{Na}_{\mathrm{v}} 1.7$ ion channel compared with other sodium ion channel subtypes). ${ }^{32} \mathrm{Na}_{\mathrm{v}} 1.7$ has been implicated as a target for the treatment of chronic pain after loss-of-function mutations in the corresponding SCN9A gene left their carriers unable to feel pain, with seemingly no other detrimental effects on their health. ${ }^{33}$ By contrast, gain-of-function mutations on the same gene cause sufferers to feel a constant burning sensation, usually in their hands and feet. ${ }^{34}$ Recently, the NMR structure of ProTx-II and analogues has been solved (PDB ID: 2N9T) ${ }^{35}$ Park and co-workers have also elucidated the solution structure of ProTx-II by NMR, ${ }^{36}$ and both structures show that the peptide adopts a classical ICK knot structure with a conformationally labile region at the $\mathrm{C}$-terminus.

Despite these structural studies, much remains unknown about the mechanism of action of ProTx-II on $\mathrm{Na}_{\mathrm{v}} 1.7$. Structural and mutagenesis investigations of the interaction of ProTx-II with the $\mathrm{Na}_{\mathrm{v}} 1.5$ ion channel established that ProTx-II does not act by blocking the channel pore. ${ }^{37}$ Instead, studies into the interaction of ProTx-II and HwTx-IV with $\mathrm{hNa}_{\mathrm{v}} 1.7$ proposed that both peptides interact with the domain II voltage-sensing domain (VSD), with ProTx-II also trapping the domain IV VSD in the resting configuration. ${ }^{38}$ Mutagenesis experiments on ProTx-II by Park and co-workers, ${ }^{36}$ and investigations of chimeric peptides incorporating sequences from the related toxin PaTx-I, have revealed that the C-terminal domain is especially important for the specificity and potency of its interaction with $\mathrm{Na}_{\mathrm{v}} 1.7$, and that certain C-terminal modifications can improve the potency relative to the wildtype (wt) peptide. Henriques and co-workers ${ }^{35}$ noted that ProTx-II potency is correlated with its membrane-binding ability, and they established the importance of certain residues in the main body of the peptide in binding to membranes. Based on these results, they proposed a model for ProTx-II inhibition of $\mathrm{Na}_{\mathrm{v}} 1.7$ where binding to the membrane orientates the peptide, which allows for the C-terminal domain to interact with the VSD of $\mathrm{Na}_{\mathrm{v}} 1.7$. Recently, Flinspach and co-workers ${ }^{39}$ identified JNJ63955918, a potent and selective inhibitor of $\mathrm{Na}_{\mathrm{v}} 1.7$, from a library of over 1500 peptides generated using ProTx-II as a scaffold, and Deuis and co-workers have characterized the mode of action of another highly selective $\mathrm{hNa}_{\mathrm{v}} 1.7$ ICK spider venom peptide, Pn $3 \mathrm{a} .{ }^{40}$ While these studies have considerably advanced our understanding of ProTx-II inhibition of $\mathrm{Na}_{\mathrm{v}} 1.7$, we do not yet have a comprehensive understanding of the binding mode of ProTx-II, or how inhibition of $\mathrm{Na}_{\mathrm{v}} 1.7$ relates to analgesia: injections of ProTx-II failed to elicit analgesia in a mouse model. ${ }^{4}$ Further studies relating the structure and function of ProTx-II are therefore vital in elucidating its mechanism of action, which will be key to designing future effective treatments for chronic pain. 


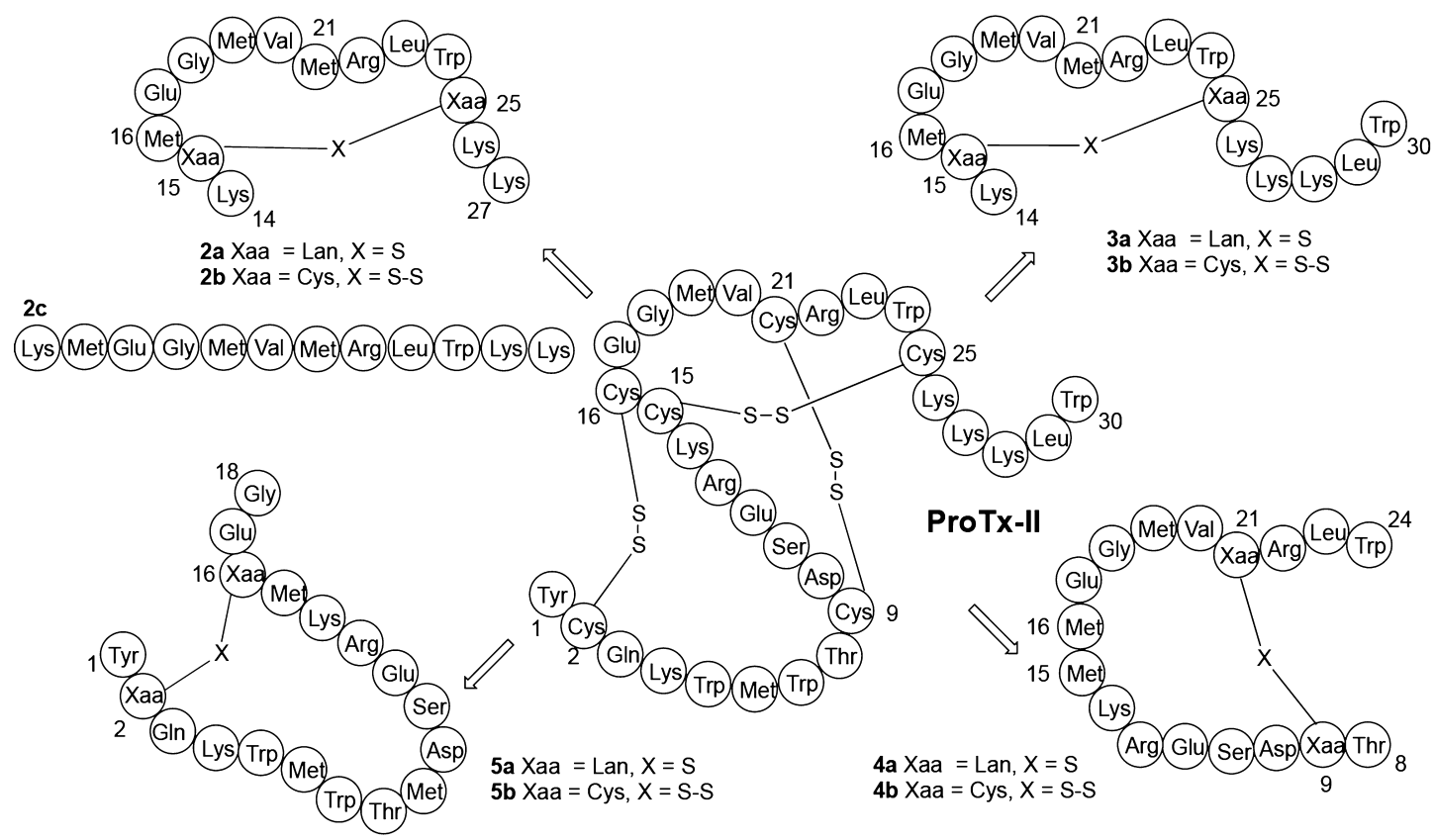

Figure 2. Single ring thioether and disulfide analogues of ProTx-II. The positions of the Cys groups, and their Met replacements, are marked according to the numbering from the full-length wt ProTx-II sequence.

Scheme 1. Synthesis of Lanthionine-Bridged Peptide $2 \mathrm{a}^{a}$

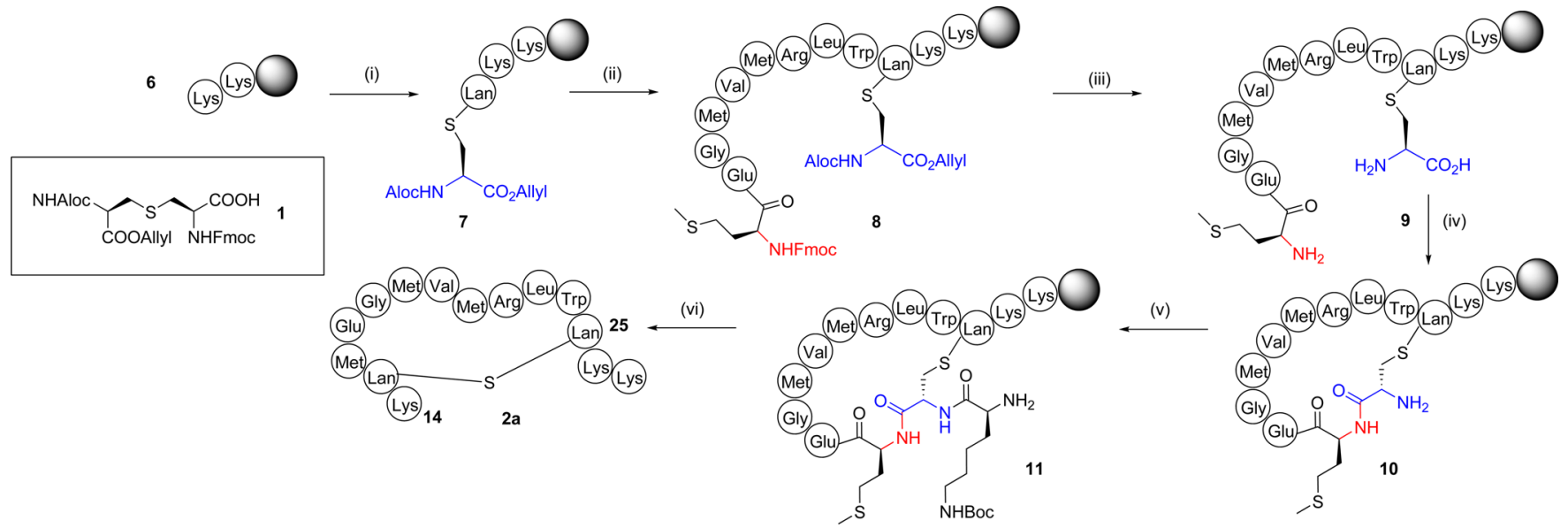

${ }^{a}$ Reagents and conditions: (i) (allyl, Aloc/Fmoc)-lanthionine 1, PyAOP, HOAt, DIPEA, DMF, $\mu$ wave, 5 min, $60{ }^{\circ} \mathrm{C}$; (ii) incorporation of standard

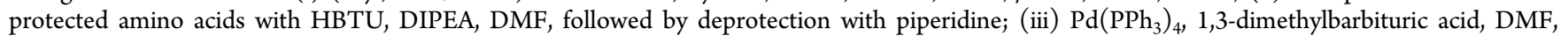
$\mathrm{CH}_{2} \mathrm{Cl}_{2}$, then $40 \%$ piperidine/DMF; (iv) PyAOP, HOAt, DIPEA, DMF, $\mu$ wave, 5 min, $60{ }^{\circ} \mathrm{C}$; (v) Fmoc-Lys(Boc)-OH, HBTU, DIPEA, DMF, then $20 \%$ piperidine/DMF; (vi) TFA, ethanedithiol, ${ }^{\mathrm{i}} \mathrm{Pr}_{3} \mathrm{SiH}_{1} \mathrm{H}_{2} \mathrm{O}$.

Our goal in this research was to use and extend our solidphase synthesis methodology to prepare lanthionine-bridged analogues of ProTx-II and of individual rings of ProTx-II. We sought to explore the effects of subtle changes in peptide conformation arising from replacing each of the naturally occurring disulfide bridged rings in turn with a thioether linked ring on the binding of these peptides to $\mathrm{hNa}_{\mathrm{v}} 1.7$ ion channels in vitro using patch-clamp assays. As part of this study, we have also investigated the effects of using different oxidative folding methods on the disulfide connectivity of the wt peptide sequence and their consequences for the biological activity of ProTx-II. Finally, we report the high-resolution X-ray crystal structure of wt ProTx-II.

\section{RESULTS AND DISCUSSION}

Synthesis of $(2 R, 6 R)-($ Allyl, Aloc/Fmoc)-Lanthionine (1). In the naturally occurring lantibiotics, the lanthionine residues are present as the meso- $(2 R, 6 S)$ diastereoisomer. However, in ProTx-II all the constituent amino acids, including the Cys residues, are the naturally occurring L-enantiomers. In order to synthesize analogues of ProTx-II with the Cys-Cys bridges replaced by lanthionine bridges with the same stereochemistry, we adapted our previously published procedure $^{21}$ to give the key orthogonally protected $(R, R)$-lanthionine building block 1 . Minor modifications to the original synthetic methodology were made in order to scale up the procedure to give multigram quantities of $\mathbf{1}$ (Supporting Information). ${ }^{41}$

Synthesis of Single Ring Truncated Analogues of ProTx-II Containing Thioether or Disulfide Bridges. 

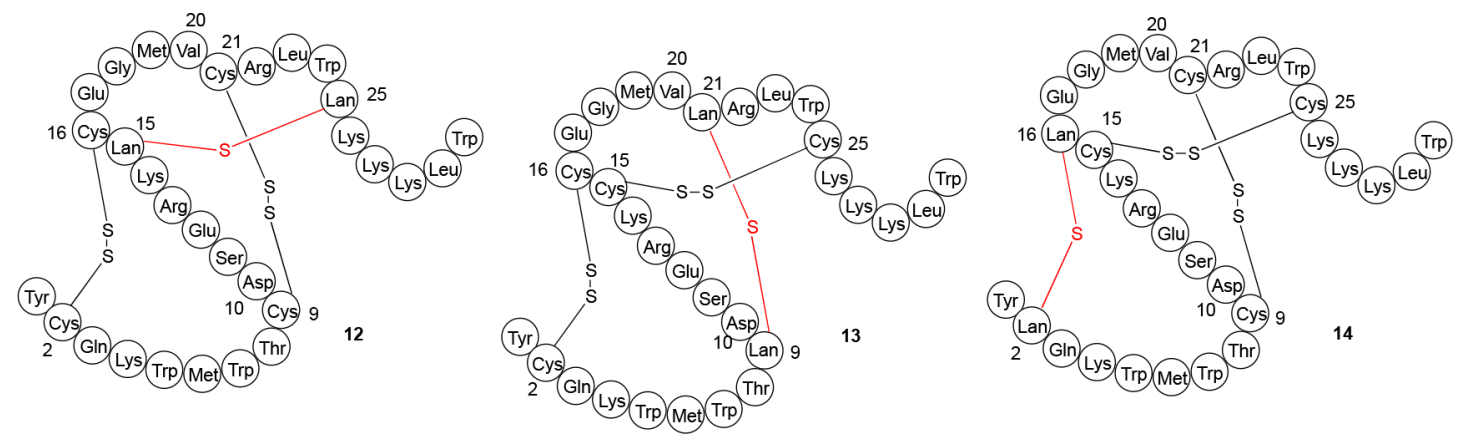

Figure 3. Lanthionine-bridged analogues of ProTx-II.

Scheme 2. Synthesis of Lanthionine-Bridged ProTx-II Analogue $12^{a}$

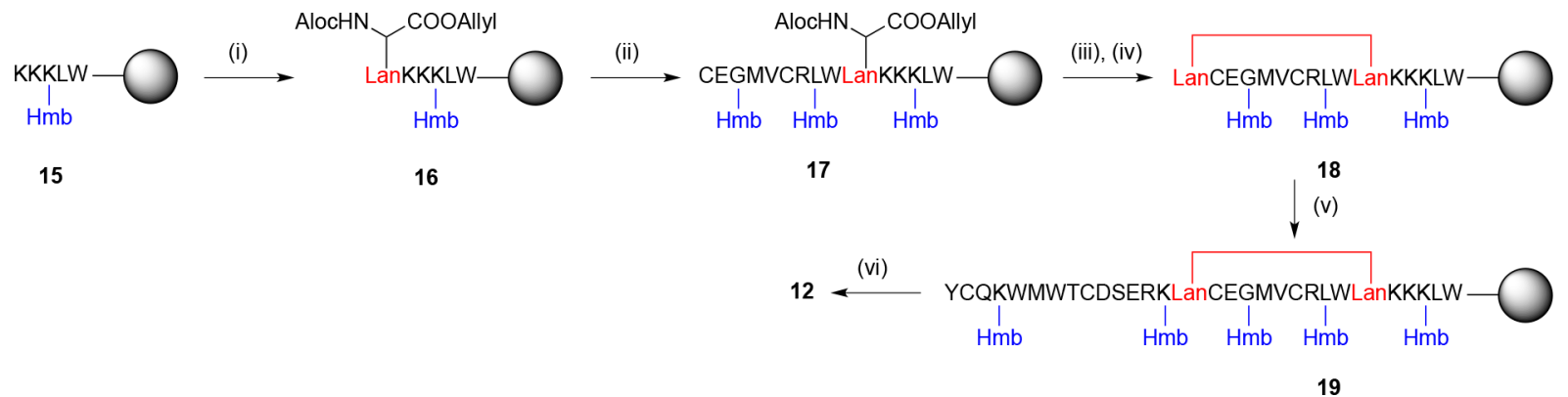

${ }^{a}$ Standard protecting groups were used for the amino acids, with additional Hmb protection as indicated; see Experimental Section. Reagents and conditions: (i) 1, PyAOP, HOAt, DIPEA, DMF, $\mu$ wave, $5 \mathrm{~min}, 60^{\circ} \mathrm{C}$; (ii) incorporation of standard protected amino acids with HBTU, DIPEA, $\mathrm{DMF}$, followed by deprotection with piperidine; (iii) $40 \%$ piperidine/DMF, then $\mathrm{Pd}\left(\mathrm{PPh}_{3}\right)_{4}, 1,3$-dimethylbarbituric acid, $\mathrm{DMF}, \mathrm{CH} \mathrm{Cl}_{2} ;$ (iv) PyAOP, HOAt, DIPEA, DMF, $\mu$ wave, 5 min, $60^{\circ} \mathrm{C}$; (v) incorporation of standard protected amino acids with HBTU, DIPEA, DMF, followed by deprotection with piperidine; (vi) TFA, ${ }^{\mathrm{i}} \mathrm{Pr}_{3} \mathrm{SiH}, \mathrm{H}_{2} \mathrm{O}$.

Before embarking on the synthesis of complex cystine knot structures containing both disulfide and thioether linkages, we elected to synthesize analogues of individual rings of ProTx-II, incorporating either thioether or disulfide bridges (Figure 2). Previous work in our group ${ }^{21}$ and by others ${ }^{24,25}$ has enabled cyclic lanthionine-bridged peptides with up to nine residues in the ring to be synthesized using this solid-phase approach. We envisaged that some development of the methodology would be needed to access lanthionine-bridged analogues of ProTx-II with up to 13 residues in the ring. Moreover, producing smaller fragments of ProTx-II would enable us to determine whether any biological activity would remain in the individual rings once removed from the highly ordered framework of the ICK structure.

Indeed, a trial synthesis of the C-terminal ring 2a using standard peptide coupling conditions at room temperature revealed problems. Linear peptide 6 was prepared on a lowloading NovaSyn TGT resin, and lanthionine derivative $\mathbf{1}$ was then coupled using PyAOP, HOAt, and DIPEA to give 7. This was then elongated to give the linear peptide 8 (Scheme 1).

We then envisaged chemoselective removal of the allyl and Aloc groups, followed by Fmoc deprotection, cyclization onresin, installation of the final amino acid, and cleavage from resin. However, this synthetic sequence yielded only small amounts of the desired 2a, mixed with linear peptide byproducts in which the lanthionine residue had not been incorporated. We therefore investigated conditions for the incorporation of $\mathbf{1}$ using microwave irradiation coupling conditions. $^{41}$ Coupling with PyAOP/HOAt/DIPEA using microwave irradiation at $300 \mathrm{~W}$ and $60{ }^{\circ} \mathrm{C}$ for 5 min proved to be optimal for incorporating 1 to give resin-bound intermediate 7. Standard SPPS was then used to elongate this to give resin-bound peptide 8 . The allyl and Aloc groups were then selectively removed with $\mathrm{Pd}\left(\mathrm{PPh}_{3}\right)_{4}$ using 1,3-dimethylbarbituric acid as an allyl group scavenger; ${ }^{42,43}$ subsequent removal of the Fmoc group gave 9. This was then selectively cyclized on-resin with PyAOP/HOAt/DIPEA, ${ }^{44}$ again using microwave irradiation at $300 \mathrm{~W}$ and $60{ }^{\circ} \mathrm{C}$ for $5 \mathrm{~min}$. Chain extension of $\mathbf{1 0}$ to give $\mathbf{1 1}$ was followed by resin cleavage to give analogue 2a. Using this approach, we also synthesized a second analogue, $3 \mathrm{a}$, as it has recently been shown ${ }^{36}$ that the flexible C-terminal fragment of ProTx-II is important for both potency and sodium channel selectivity. Pleasingly, we were also able to prepare the lanthionine analogue of the larger ( 13 residues) central ring, 4a. However, unfortunately the largest (15 residues) ring, 5a, could not be synthesized. For comparison purposes, the Cys-linked disulfide analogues $\mathbf{2 b}$, $\mathbf{3 b}, \mathbf{4 b}$, and $\mathbf{5 b}$ were also synthesized. In each case the linear peptides were prepared using standard techniques (Supporting Information) and then cyclized by stirring for 10 days at $4{ }^{\circ} \mathrm{C}$ in water, giving the desired peptides in good yield and purity.

Synthesis of Full-Length ProTx-II Analogues with One Disulfide Bridge Replaced by a Thioether Bridge. Having successfully prepared the single ring analogues, we turned our attention to the full length analogues 12, 13, and 14 (Figure 3). Our strategy for these peptides had to take into account two possible challenges. The first is that the thioether bridges in lantibiotics are very susceptible to aerial oxidation, ${ }^{45}$ and therefore prolonged reaction times when forming the Cys-Cys bridges should be avoided. The second problem that we anticipated, in particular after the formation of the lanthionine bridge, was the folding or aggregation of the resin-bound 
Scheme 3. Synthesis of Lanthionine-Bridged ProTx-II Analogue $13^{a}$

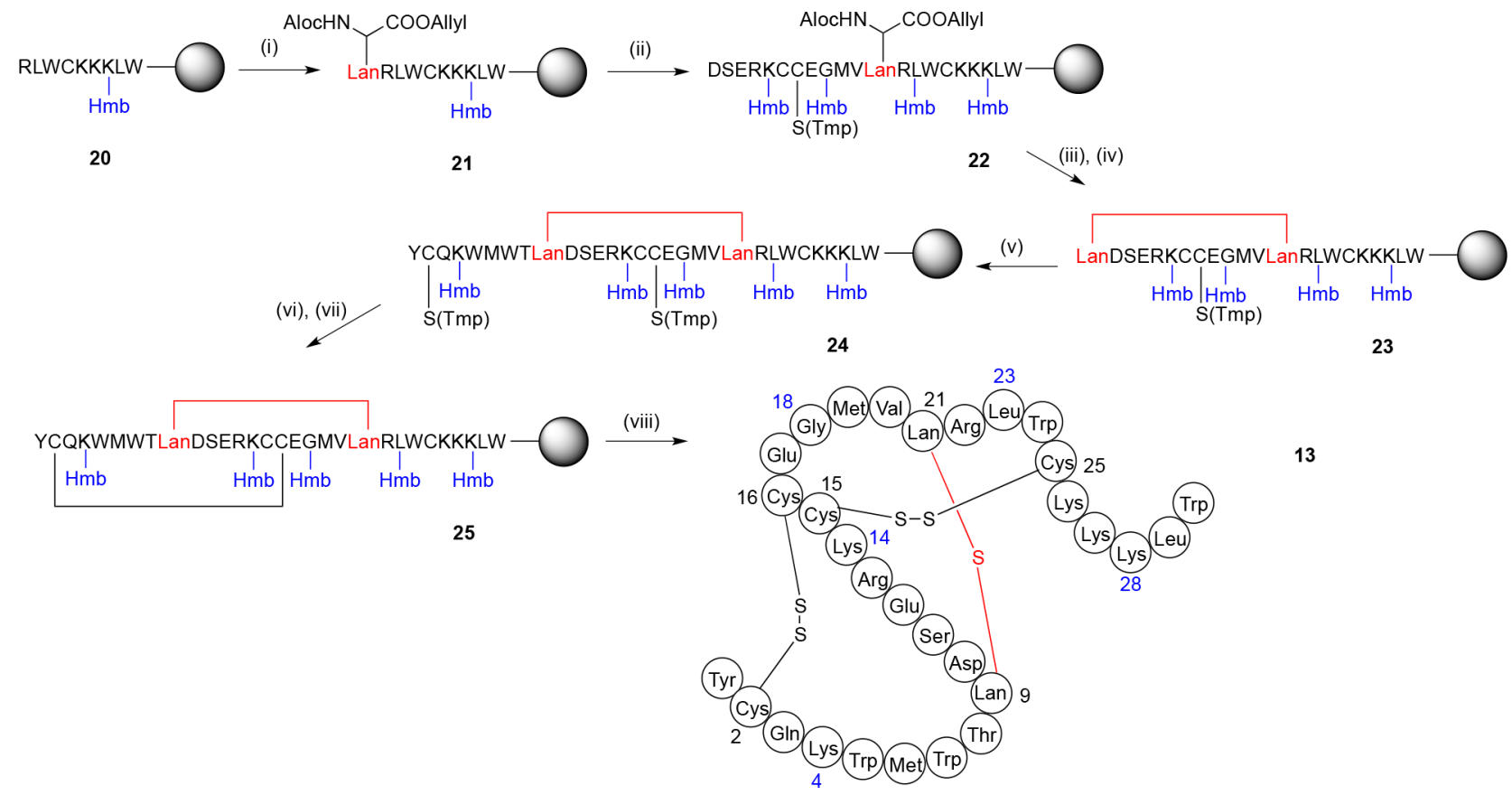

${ }^{a}$ Standard protecting groups were used for the amino acids, with additional Hmb protection as indicated; see Experimental Section. Reagents and conditions: (i) 1, PyAOP, HOAt, DIPEA, DMF, $\mu$ wave, $5 \mathrm{~min}, 60^{\circ} \mathrm{C}$; (ii) incorporation of standard protected amino acids with HBTU, DIPEA, DMF, followed by deprotection with piperidine; (iii) $40 \%$ piperidine/DMF, then $\mathrm{Pd}\left(\mathrm{PPh}_{3}\right)_{4}, 1,3$-dimethylbarbituric acid, $\mathrm{DMF}, \mathrm{CH} \mathrm{Cl}_{2}$; (iv) PyAOP, HOAt, DIPEA, DMF, $\mu$ wave, 5 min, $60^{\circ} \mathrm{C}$; (v) incorporation of standard protected amino acids with HBTU, DIPEA, DMF, followed by deprotection with piperidine; (vi) 5\% DTT in $0.1 \mathrm{M}$ NMM, DMF; (vii) NCS (2 equiv), DMF; (viii) TFA, ${ }^{\mathrm{i}} \mathrm{Pr}_{3} \mathrm{SiH}_{1} \mathrm{H}_{2} \mathrm{O}$.

peptide during synthesis, resulting in the $N$-terminal amino acid becoming inaccessible to subsequent activated amino acids. In the event this proved to be a more serious problem. Attempted solid-phase synthesis of the linear peptides failed in each case shortly after incorporation of the first lanthionine residue, even when microwave coupling conditions were used, resulting in the isolation of short peptides of between 6 and 12 residues. In order to circumvent this problem, we inserted $\mathrm{Hmb}$-protected amino acids at positions $4,14,18,23$, and 28 , in order to disrupt hydrogen bonding and prevent on-resin aggregation. ${ }^{46}$ For analogue 12, we also elected to use the same protecting groups for the Cys residues at positions 2, 9, 16, and 21. We anticipated that the presence of the thioether bridge between positions 15 and 25 would enable the peptide to fold correctly and the Cys-Cys bridges to be formed with the correct connectivity, without the need for an orthogonal Cys side-chain protecting strategy. Thus, (Scheme 2) protected lanthionine 1 was coupled to the resin-bound peptide 15 using the microwave conditions optimized for the single ring analogues. Chain extension of $\mathbf{1 6}$ using standard coupling conditions, and Hmb-protected amino acids as indicated, afforded 17. The lanthionine bridge was then formed by sequential removal of the Fmoc and allyl/Aloc protecting groups, followed by microwave-assisted cyclization on-resin, as before.

Chain extension of $\mathbf{1 8}$ gave the fully protected, resin-bound peptide intermediate 19. Subsequent cleavage of 19 from the resin, using a deprotection cocktail lacking EDT, gave the desired fully deprotected and cyclized peptide $\mathbf{1 2}$ (overall yield $0.4 \%$ after purification). This suggests that the partly folded, lanthionine-bridged structure does indeed aid the cyclization of the disulfide bonds during the cleavage and deprotection procedure. The same strategy was used to synthesize 14 in a yield of $1.1 \%$ after purification.

For analogue 13, as the third and fourth cysteine residues are next to each other in this sequence, we decided to employ orthogonal protecting group chemistry in order to guarantee the 1-4, 3-6 connectivity. We elected to use $S(\mathrm{Tmp})$-protected cysteine $^{47}$ as this protecting group is stable to piperidine but very labile under mild thiolysis conditions, for example in the presence of DTT. Thus, (Scheme 3) 1 was coupled to linear resin-bound peptide 20 using microwave coupling conditions to give 21, and chain extension as before afforded 22 . Deprotection of Fmoc and allyl/Aloc protecting groups, followed by microwave-assisted cyclization on-resin, gave 23, which was again chain-extended to give the resin-bound peptide 24. On-resin cleavage of the Tmp protecting groups with DTT was followed by oxidation with NCS to give the bicyclic resinbound peptide 25. Cleavage and deprotection using the same deprotection cocktail, lacking EDT, followed by stirring in water at $4{ }^{\circ} \mathrm{C}$, gave the desired tricyclic peptide 13 in $7 \%$ yield after purification.

As a control for the biological testing, we also synthesized the parent ProTx-II structure. The linear sequence was prepared using standard SPPS protocols (Supporting Information) and purified. Despite reports of racemization of cysteine residues under these conditions, ${ }^{48}$ substitution of DIPEA as the base in the coupling step with 2,4,6-collidine did not noticeably improve the purity of the crude linear ProTx-II produced. Although formation of the correct connectivity of the three disulfide bonds in these toxins is clearly crucial for folding of the peptide into the biologically active structure, achieving regioselective disulfide bond formation is difficult to achieve using orthogonal protecting groups for three pairs of Cys 
residues. ${ }^{49}$ Conotoxins with three disulfide bridges are typically synthesized as a linear precursor with all six cysteines unprotected, and then different oxidation methods are attempted until the correct topology is formed. The wide variation in peptide sequence has precluded the development of a single, general method for such cyclizations. ${ }^{50}$ Intriguingly, in some cases oxidative folding of linear conotoxin precursors has resulted in two disulfide isoforms, both of which have potent $\mathrm{Na}_{\mathrm{v}}$ channel blocking activity. ${ }^{51}$ However, for this family of spider toxins there are no reports comparing the effectiveness and selectivity of different oxidative cyclization methods. Initial attempts to cyclize the linear, unprotected ProTx-II peptide sequence using the conditions reported by Middleton ${ }^{26}$ were unsuccessful in our hands. We next turned to aerobic oxidation, ${ }^{49}$ and after some investigation we determined that the purified, unprotected linear ProTx-II peptide could be cyclized in $\mathrm{H}_{2} \mathrm{O}$ at $10{ }^{\circ} \mathrm{C}$ and a concentration of $0.1 \mathrm{mg} / \mathrm{mL}$ over 7 days to give the cyclized peptide (ProTx-II/7d) cleanly and in high yield. For comparison, ProTx-II was prepared using the conditions recently described by Park and co-workers. ${ }^{36}$ In this procedure, the unpurified, unprotected linear ProTx-II peptide was stirred at $\mathrm{pH} 8$ in a mixture of glutathione (GSH), glutathione disulfide (GSSG), urea, and Tris- $\mathrm{HCl}$ for $24 \mathrm{~h}$, followed by adjustment to $\mathrm{pH} 3$ and purification of the peptide by HPLC to yield the cyclic peptide (ProTx-II/24h). As additional controls, we also purchased commercial samples of ProTx-II from two companies, Sigma-Aldrich and Smartox.

Biological Activity of ProTx-II and Analogues. All compounds were tested against stably transfected cell lines expressing the $\mathrm{hNa}_{\mathrm{v}} 1.7$ receptor, using the $\mathrm{hNa}_{\mathrm{v}} 1.7-\mathrm{HEK}$ cell IonWorks Population Patch Clamp Assay (Essen) and the QPatch Patch Clamp Assay (B'SYS GmbH). Perhaps unsurprisingly, neither the single ring lanthionine analogues $\mathbf{2} \mathbf{a}-\mathbf{4 a}$, nor their Cys-Cys counterparts $\mathbf{2} \mathbf{b}-\mathbf{5 b}$, showed any activity in these assays. Disappointingly, the full-length lanthionine bridged analogues 12, 13, and 14 did not show any activity either. Finally, to our surprise, the wt ProTx-II/7d that we had synthesized was completely inactive, as was the sample purchased from Sigma-Aldrich, whereas the ProTx-II/ 24h sample, and the sample from Smartox, showed the expected activity (Supporting Information).

Disulfide Connectivity and Conformation of wt ProTxII Prepared by Different Oxidative Folding Methods. Liquid chromatography-mass spectrometry (LC-MS) showed that all four samples of wt ProTx-II had the correct amino acid composition and initially appeared to indicate that all three disulfide bonds had formed in each sample. The peptide samples were then compared by HPLC, and a clear difference was seen between the retention times of the ProTx-II/7d and the ProTx-II/24h peptides; this was verified by co-injection of the two samples (Figure 4).

This was further confirmed by comparing the HPLC trace of the ProTx-II/24h peptide with the Smartox sample (Supporting Information Figure S1b) and the ProTx-II/7d peptide with the Sigma sample (Supporting Information Figure S1c). This strongly suggested that the ProTx-II/24h peptide had either a different conformation or different disulfide bond connectivity to the ProTx-II/7d peptide.

Investigation of Disulfide Bond Connectivities of the ProTx-II Peptides by Mass Spectrometry. We reasoned that the differences in biological activity and HPLC retention time might arise from differences in disulfide bond connectivity between the two groups of peptides. In particular, because the

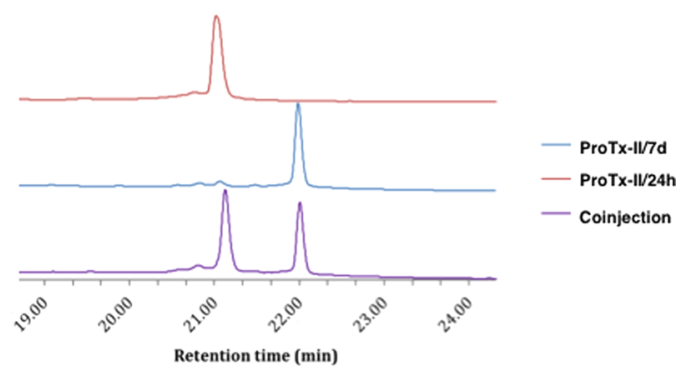

Figure 4. HPLC of ProTx-II/24h and ProTx-II/7d peptides. All experiments were run using analytical HPLC Method B.

Cys residues at positions 15 and 16 are adjacent, it was conceivable that one group of peptides might have the 1-4, 2-5, and 3-6 connectivity pattern observed for ICK knot peptides, and the other group might have a different connectivity, such as the 1-3, 2-5, and 4-6 pattern observed in spider toxins such as huwentoxin-II (HwTx-II). ${ }^{52}$ To investigate this possibility, proteolytic digestion of the peptide samples, followed by sequencing of the resulting products by mass spectrometry, was attempted following the method of Middleton et al. ${ }^{26}$ In our hands, however, the sequencing experiments could not be reproduced, and enzymatic digestion did not conclusively determine the disulfide bond connectivity.

We therefore decided to examine in more detail the intact forms of the peptide by means of nano-electrospray ionization (nanoESI) and ion mobility mass spectrometry (IM-MS). IMMS can separate ions based on their mass, charge, and overall shape and has been successfully used to separate peptides of the same sequence but differing modification states. ${ }^{53,54} \mathrm{We}$ hypothesized that any differences observed in the IM-MS data between these two peptides were likely to be due to differences in shape, which could in turn be caused by differences in disulfide bond connectivity. The nanoESI spectra of ProTx-II/24h and ProTx-II/7d samples are shown in Figure 5. The charge state distribution differs between the two samples, with the ProTx-II/24h exhibiting an overall lower charge state which is indicative of a more folded structure. ${ }^{55}$

A closer inspection of the +4 charge state from both peptides revealed differences in the isotopic distribution (Figure 6). We simulated the theoretical isotopic distribution for a ProTx-II peptide which would be either fully oxidized or fully reduced.

Comparison of the experimental and theoretical isotope distributions revealed that, while the ProTx-II/24h sample corresponds to a peptide with all cysteines oxidized, the ProTxII/7d appears to be a mixture of oxidized and fully reduced species. To probe this even further we carried out IM-MS analyses of the +4 charge state. Figure 7 shows the arrival time distributions (ATDs) for the two peptides. While the ATD of ProTx-II/24h comprises one peak, the same is not true for the ProTx-II/7d peptide. The ATD for the ProTx-II/7d peptide is broad and consists of more than one peak, signifying the existence of multiple different species being present. Reconstructing the mass spectra that correspond to each region of the ATD for the ProTx-II/7d sample, further reveals that none of these co-existing forms of this peptide are in the fully oxidized state as indicated by the isotopic ratio.

Our native and IM-MS studies, therefore, show that the two peptides differ in the extent of disulfide bond formation, and this may be responsible for the difference in activity against the target sodium channel. 


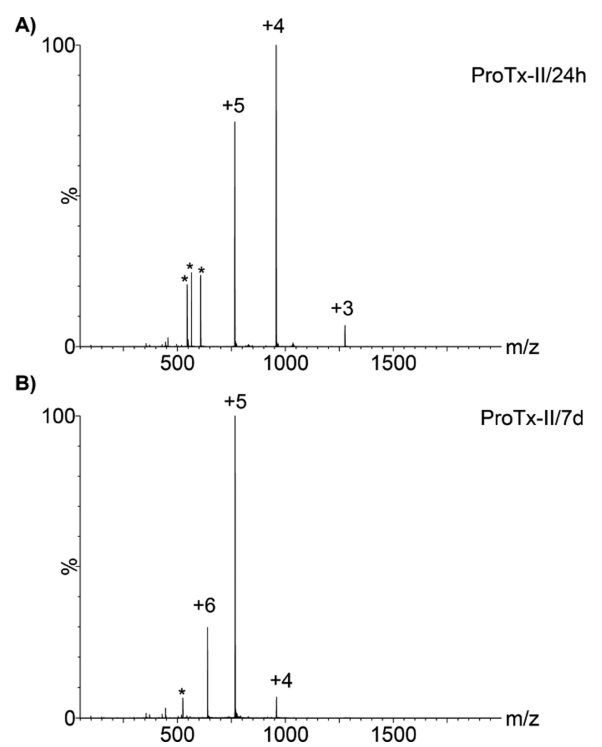

Figure 5. NanoESI spectra of (A) ProTx-II/24h and (B) ProTx-II/ $7 \mathrm{~d}$ peptides. The predominant charge states observed are +4 and +5 for the ProTx-II/24h and ProTx-II/7d, respectively. Peaks annotated with * correspond to contaminant species.

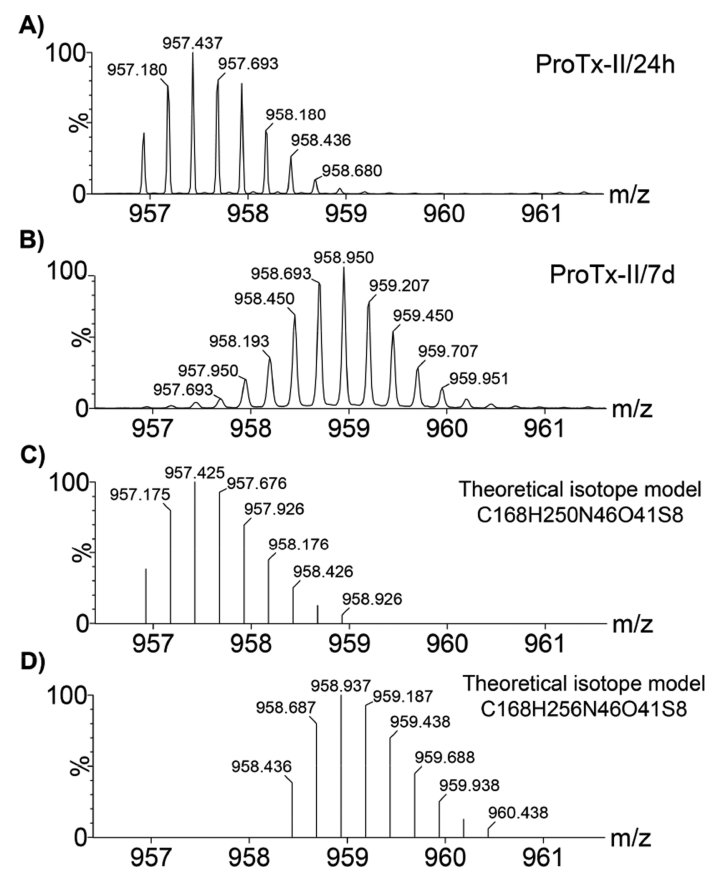

Figure 6. Zoom-in of the +4 charge states of (A) ProTx-II/24h and (B) ProTx-II/7d peptides and theoretical isotope distribution corresponding to a ProTx-II with (C) all cysteines oxidized and (D) all cysteines reduced.

Crystal Structure of ProTx-II. To confirm the disulfide bond connectivity of the biologically active ProTx-II, we investigated its structure by X-ray crystallography. The structures of spider venom peptides have generally been studied to date by NMR; this is because their relatively small size makes solving the structure by this method feasible, but is also due to the reported difficulty in growing suitable crystals for X-ray crystallography. ${ }^{29}$ In fact, although the structures of several ICK peptides have been determined using NMR, to date only one ICK spider-venom toxin, ceratotoxin (CcoTx-I)

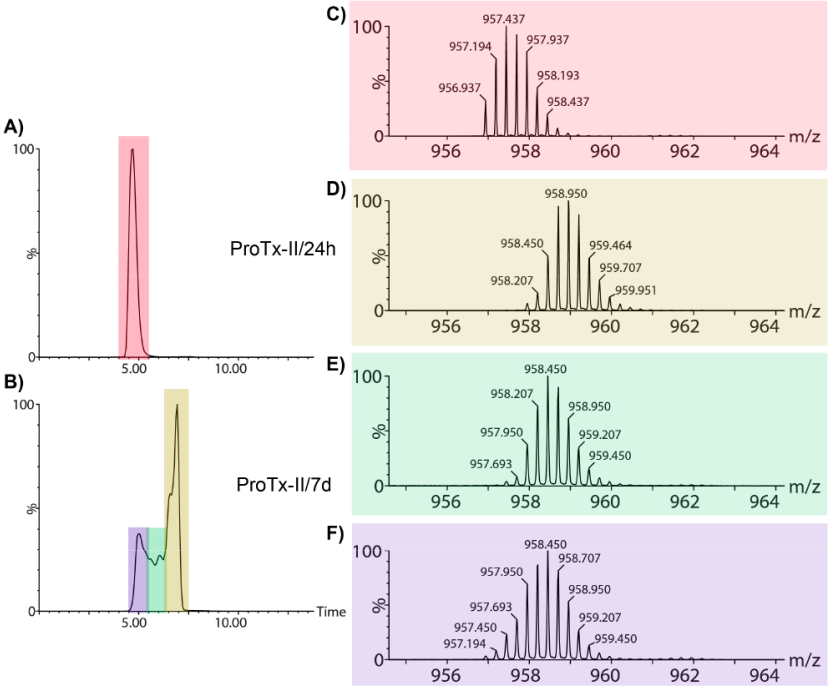

Figure 7. Arrival time distribution (ATD) from the IM-MS analysis of the +4 ion for (A) ProTx-II/24h and (B) ProTx-II/7d peptides. (C) The corresponding mass spectrum for ProTx-II/24h and (D-F) mass spectra corresponding to the different colored ATD regions for ProTx-II/7d.

has been successfully characterized by X-ray crystallography (PDB ID: 5EPM); ${ }^{29}$ moreover, in this structure, the target peptide was bound to a specifically generated high-affinity antibody Fab fragment to aid crystallization. This work represents the first reported crystal structure of ProTx-II and, to our knowledge, is the first crystal structure of any unbound ICK peptide toxin from spider venom.

A sample of ProTx-II known to be active against $\mathrm{Na}_{\mathrm{v}} 1.7$ was crystallized, and the crystal diffracted well under synchrotron conditions. The atomic resolution structure $(0.99 \AA)$ corroborates many features of the previously published structure solved by NMR (PDB ID: 2N9T). ${ }^{35}$ The disulfide bonds can be clearly resolved in the electron density, with the peptide showing the expected ICK fold and disulfide bond arrangement $(1-4,2-5,3-6)$, together with a largely rigid and hydrophobic central core and more conformationally labile Cand N-termini. The RMSD for the full-length peptide all-atom/ $\mathrm{C} \alpha=3.19 \AA / 2.07 \AA$, whereas with the $\mathrm{N}$ - and C-termini removed the RMSD are all-atom $/ \mathrm{C} \alpha=2.26 \AA / 1.36 \AA$, highlighting the fact that most of the variability in the structure lies in the termini. In contrast to $2 \mathrm{~N} 9 \mathrm{~T}$, but consistent with other ICK peptides whose structures have been determined, our structure shows evidence of hydrogen bonding consistent with a beta hairpin from residues 19 to 27 . The overall fold is similar to that reported in 2N9T, but with some deviations around M6 and L23; these could be a true reflection of the structure or represent the effects of crystal packing.

Two conformations of the $\mathrm{N}$-terminal Y1 were observed in the electron density map. The crystal structure also shows the same hydrogen-bond interactions between the side chains of D10 and R13 seen in the NMR models (Figure 8), and a hydrogen bond between the side chain of $\mathrm{E} 3$ and the backbone of T8, which are not found in 2N9T. Further hydrogen bonds between the peptide backbone atoms, notably E3-K14, C9-L23 and M6-C25 give greater stability to the overall fold. Ultimately, the crystal structure provides conclusive proof that the biologically active form of ProTx-II adopts the ICK fold. 


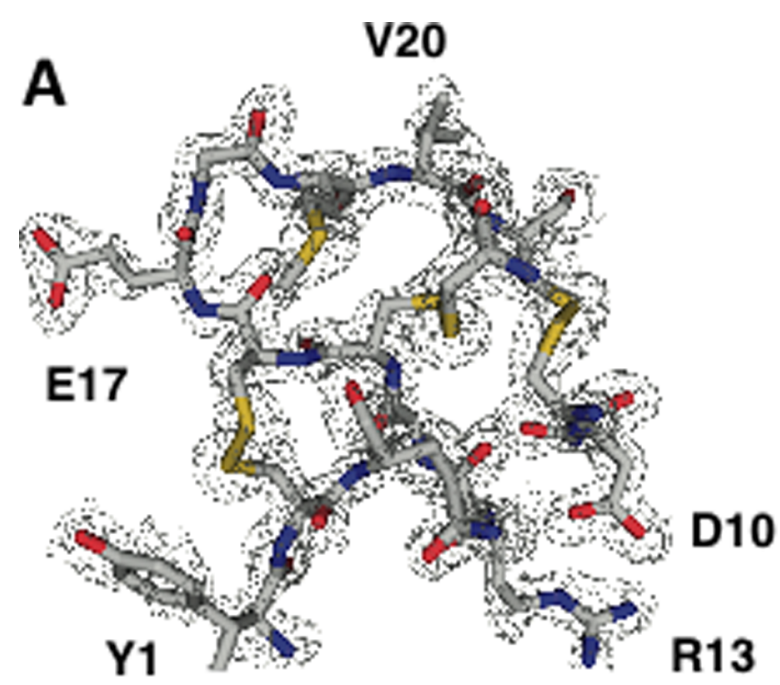

B
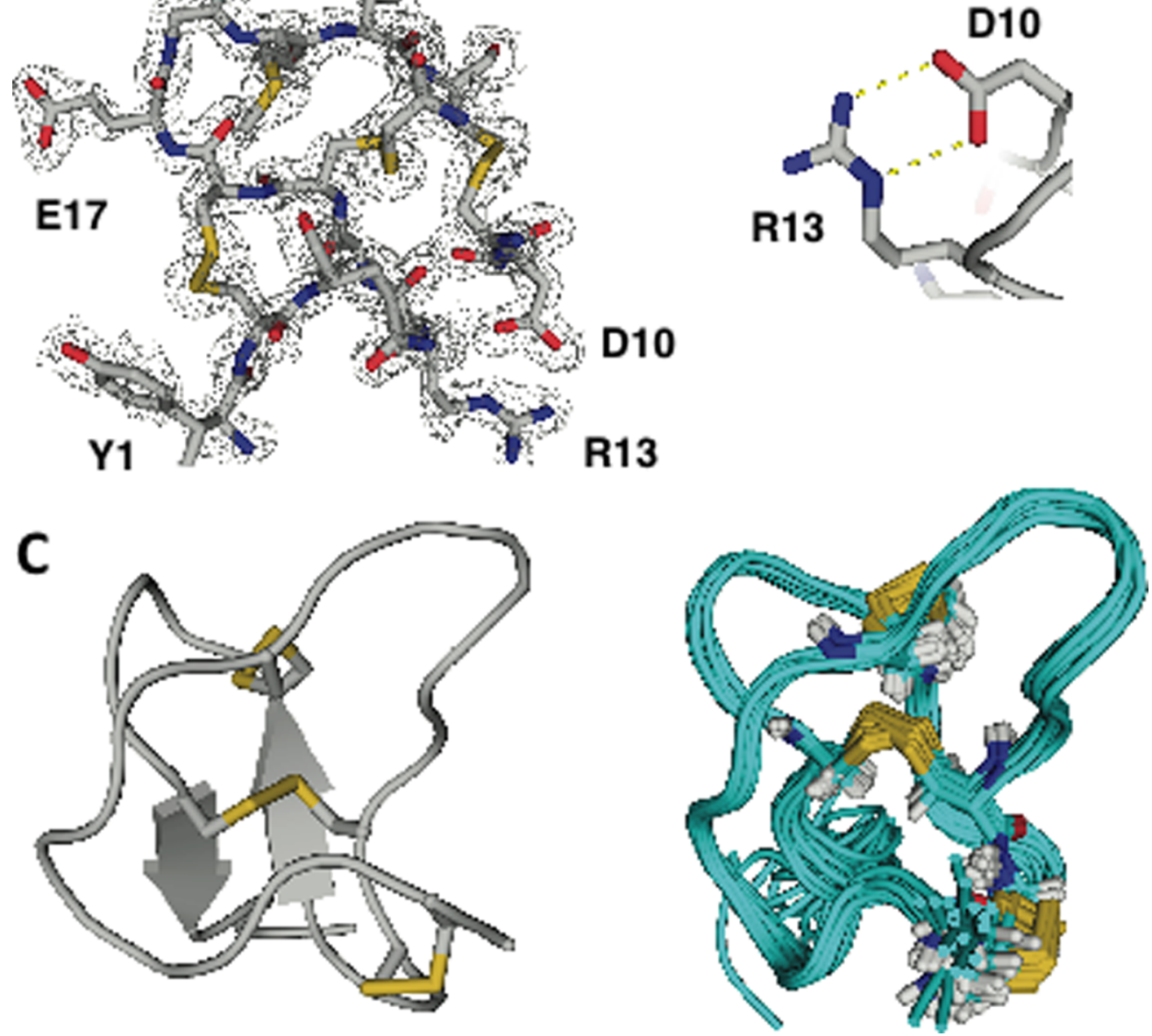

Figure 8. (A) 2Fo-Fc Electron density map calculated using experimental phases, showing traceable peptide backbone and well-resolved side chains. (B) Fragment of ProTx-II crystal structure showing hydrogen bonding between R13 and D10. (C) Comparison of the X-ray crystal structure (left) with previously published NMR ensemble (PDB ID: 2N9T) showing similar overall folding and structure.

\section{CONCLUSIONS}

In this paper, we report the synthesis of three synthetic analogues of the ICK scaffold spider toxin ProTx-II, where each of the three disulfide bridges is regioselectively replaced by a thioether linkage. Incorporation of orthogonally protected $(2 R, 6 R)$-lanthionine via solid-phase synthesis, followed by selective deprotection and on-resin cyclization, has enabled us to achieve for the first time the synthesis of highly complex triply bridged peptides with two cystine bridges and one lanthionine bridge. Moreover, in this work we have also demonstrated that very large lanthionine-bridged rings (up to 15 residues for peptide 14) can be synthesized by this approach.

These lanthionine-bridged peptides have larger ring sizes than those found in the naturally occurring lantibiotics, demonstrating the power of this approach for designing and synthesizing conformationally constrained peptides. It therefore also enables another approach for the modification of naturally occurring spider venom toxins as leads for potent and selective sodium channel blockers with good pharmacokinetic properties, complementary to the mutagenesis and chimeric peptide approaches previously published. ${ }^{28,29,35,36,56}$

Although lanthionine- and selenolanthionine-bridged analogues of other biologically active cyclic peptides have previously been reported to maintain or increase potency and stability relative to cystine-bridged peptides, ${ }^{18-20}$ this approach was not successful in delivering potent or selective $\mathrm{Na}_{\mathrm{v}} 1.7$ channel blockers based on ProTx-II. This could result from a number of factors: the shorter bridge between the $\alpha$-carbons; the differences between the geometrical constraints imposed by a thioether versus a disulfide bridge; or differences in the correct folding of the resulting peptide. Indeed, a recent NMR study $^{57}$ comparing thioether analogues of disulfide-bridged cyclic peptides targeting Death Receptor 5 with cystine-bridged peptides concluded that the thioether peptide was slightly less folded than the disulfide peptide.

In this regard, we have also demonstrated the importance of choosing the correct conditions for the oxidative folding of complex peptide toxins. This step is currently a bottleneck in the successful high-throughput production, and scale-up, of peptides containing multiple disulfide bridges. ${ }^{58}$ For ProTx-II, the presence of a redox buffer containing an excess of GSSG and GSH appears to be mandatory for the formation of the corrected folded toxin with all of the disulfide bridges formed (ProTx-II/24h). Conversely, it is clear from our IM-MS studies that aerial oxidation in water at neutral $\mathrm{pH}$ gives a number of products (ProTx-II/7d), none of which is in the fully oxidized state. Whether these partially cyclized peptides 
result from the kinetic formation of one or more incorrect CysCys linkages, or whether they arise from an incorrectly folded intermediate with one or more correct Cys-Cys linkages, is impossible to determine in this case, as the observed ATD distribution (Figure 7) could arise from differing collision cross sections of both incorrectly folded peptides and incomplete disulfide oxidation.

This also raises the wider issue of whether the use of aerial oxidation, rather than the GSSG/GSH buffer, for folding the lanthionine hybrids 12, 13, and 14 may have been a contributory factor to their lack of activity. An additional complication is that the methodology that we have developed for synthesizing these hybrids necessarily introduces a nonreducible linkage during the synthesis. For multiply disulfide bridged peptides and small proteins, it is widely accepted that there are several different pathways of oxidative folding. These vary from one extreme in which an ensemble of heterogeneous intermediates with many non-native disulfide bonds are initially generated, with these rearranging over time via disulfide shuffling to give the correctly folded and connected peptides, to the other extreme in which the amino acid sequence dictates a folding pathway which leads predominantly or exclusively to native disulfide bonds without subsequent rearrangement being necessary, with intermediate situations in which the formation of a non-native bridge creates a correctly folded peptide in which the required cysteine residues are brought into proximity, allowing reshuffling to give the correct connectivity. ${ }^{59}$ Moreover, for some peptide sequences such as tick anticoagulant peptide (TAP) it has also been shown that incorrectly folded/ connected intermediates can act as kinetic "traps", giving highly stable structures that are difficult to refold/reconnect into the correct structure. ${ }^{60}$ Thus, once a nonreducible lanthionine bridge has been introduced during the synthesis of the linear peptide, then the peptide may well have been trapped into a non-natural fold from which it cannot easily refold/rearrange to the native fold/connectivity.

Importantly, in this work we have also demonstrated the power of IM-MS studies for rapidly determining whether the oxidative folding method employed for synthetic ICK fold toxins gives a single, correctly folded and oxidized peptide or a mixture of incompletely oxidized species. We envisage that this will be particularly useful when screening libraries of peptides $^{29,39}$ based on lead peptides from spider venoms. Such libraries, whether produced by either solid-phase synthesis or recombinant expression, usually rely on aerial oxidation to form the disulfide bridges, and our present work suggests that for some sequences in these libraries, a lack of biological activity might result from misfolding or incomplete oxidation of the particular peptide.

We have also reported here the first crystal structure of an ICK peptide toxin from spider venom not bound to a substrate. Whereas the X-ray crystal structure of a much larger (278 residues) phospholipase $\mathrm{D}$ enzyme spider venom peptide has recently been reported, ${ }^{61}$ smaller $(30-35$ residue) peptides such as ProTx-II are surprisingly difficult to crystallize. Hitherto all structural studies with these ICK fold spider toxins have been carried out using NMR techniques. The high resolution of this X-ray crystal structure structure of ProTx-II has enabled hydrogen bonds which could not be seen in the NMR structures to be observed. In turn, this will shed additional light on the stabilization of the ICK fold, and may help with further analysis of the structure-activity relationships between these toxins and the sodium channel receptors.
Finally, having demonstrated the potential of this solid-phase peptide synthesis approach to the preparation of ICK fold peptide toxin analogues with Cys-Cys linkages replaced by unnatural bridges, this paves the way for the preparation of other peptide structures with different ring sizes and bridge geometry. This opens up the potential for the design of more potent and selective $\mathrm{Na}_{\mathrm{v}} 1.7$ channel blockers with better pharmacokinetic properties and metabolic stability. In addition, peptides with one side-chain bridge that is regioselectively installed and cannot be reduced may also act as tools for investigating the folding pathways of these multiply bridged peptides, in combination with the IM-MS methodology reported here. Although the presence of a nonreducible sidechain bridge could be problematic for the correct folding of some peptide sequences, conversely in some cases it also has the potential to streamline the folding pathways by diminishing the number of nonproductive conformations available ${ }^{10,58}$ and thus improving the synthetic routes to these peptides.

\section{EXPERIMENTAL SECTION}

General Experimental for Peptide Synthesis. Protected amino acids and coupling reagents were purchased from Novabiochem; coupling reagents, bases, and solvents were purchased from SigmaAldrich. All water used was either distilled using an Elga Purelab Option R 7 water purifier or used directly from a bottle of HPLCgrade water. The peptides were either synthesized using an automated peptide synthesizer or manually, using the same timings and solution volumes. Amino acid and reagent concentrations were calculated based on the quantity and loading of the resin. The total volume of all reagents in each step was $1.5 \mathrm{~mL}$. All reagents were dissolved in HPLC grade DMF.

Microwave couplings were carried out using a Personal Chemistry Smith Creator microwave loaded with $5 \mathrm{~mL}$ reaction vials. In all cases, the vial was irradiated for $5 \mathrm{~min}$ at $60{ }^{\circ} \mathrm{C}$ and $300 \mathrm{~W}$ before transfer of the resin back to the reaction syringe. DMF was used as the primary solvent throughout the peptide synthesis.

Peptides were centrifuged using an Eppendorf Centrifuge, model 5810R, and were lyophilized using a Thermo Scientific Heto PowerDry LL1500 freeze-dryer.

Automated Peptide Synthesis. Peptides were synthesized on a MultiSynTech Syro Peptide Synthesizer (Model MP-60).

Manual Peptide Synthesis. All manual coupling and deprotection steps, and complete manual peptide syntheses, were carried out using an IKA KS130 basic platform shaker to agitate the solutions. Reactions were carried out in $5 \mathrm{~mL}$ syringes with frits, which were evacuated by hand at the end of each reaction.

Fmoc Deprotection. For the automated peptide syntheses, all Fmoc deprotections were carried out using a solution of $40 \%$ piperidine in DMF, which was added to the syringe containing the resin. The mixture was agitated for $20 \mathrm{~s}$ every minute for a total of 3 min before removal of reagent by filtration under vacuum. The resin was washed with DMF $(4 \times 1.5 \mathrm{~mL})$ before addition of a second portion of piperidine in DMF solution $(40 \% \mathrm{v} / \mathrm{v}, 0.75 \mathrm{~mL})$, followed by DMF $(0.75 \mathrm{~mL})$ to make an overall $20 \% \mathrm{v} / \mathrm{v}$ solution of piperidine in DMF. This mixture was agitated for $20 \mathrm{~s}$ every minute for a total of $10 \mathrm{~min}$. The reagents were removed by filtration under vacuum, and the resin was washed with DMF $(6 \times 1.5 \mathrm{~mL})$. For the manual peptide syntheses, all Fmoc deprotections were carried out using a solution of $40 \%$ piperidine in DMF, which was added to the syringe containing the resin. The mixture was agitated for $3 \mathrm{~min}$ before removal of reagent by filtration. A second portion of piperidine in DMF solution $(40 \% \mathrm{v} / \mathrm{v}, 0.75 \mathrm{~mL})$ was added, followed by DMF $(0.75 \mathrm{~mL})$ to make an overall $20 \% \mathrm{v} / \mathrm{v}$ solution of piperidine in DMF. This mixture was agitated for a total of $10 \mathrm{~min}$. The reagents were removed by filtration, and the resin was washed with DMF $(6 \times 1.5 \mathrm{~mL})$.

Amino Acid Coupling. Fmoc-protected amino acid (4 equiv) was added to the reaction syringe with HBTU (4 equiv) and DIPEA (8 
equiv). The mixture was agitated for $20 \mathrm{~s}$ every $3 \mathrm{~min}$ for a total of 40 $\mathrm{min}$. The reagents were removed by filtration under vacuum, and the resin was washed with DMF $(4 \times 1.5 \mathrm{~mL})$.

Lanthionine Coupling. (S)-Allyl 3-((S)-2-((9-fluorenylmethoxycarbonyl)amino-3-tert-butoxy-3-oxopropylthio)-2(allyloxycarbonylamino)propanoic acid (1) (3 equiv), PyAOP (5 equiv), and HOAt (5 equiv) were dissolved in DMF ( $4 \mathrm{~mL})$. To this, $\mathrm{N}, \mathrm{N}$-diisopropylethylamine (10 equiv) was added and left to react for $1 \mathrm{~min}$ before addition to a microwave vial containing the resin. The vial was irradiated for $5 \mathrm{~min}$ at $60{ }^{\circ} \mathrm{C}$ before transfer of the resin back to the reaction syringe. The resin was then washed with DMF $(4 \times 1.5$ $\mathrm{mL}$ ).

Allyl/Alloc Deprotection. Simultaneous deprotection of both the allyl and Alloc ester groups was performed using tetrakistriphenylphosphine palladium $(0)$ (1 equiv) and 1,3-dimethylbarbituric acid (10 equiv) in a 1:1 solution of $\mathrm{CHCl}_{3}: \operatorname{DMF}(2 \mathrm{~mL})$. This was left to react for $2 \mathrm{~h}$ in the dark under argon before removal of the solution by filtration. The resin was then washed with $\mathrm{CH}_{2} \mathrm{Cl}_{2}(10 \times 1.5 \mathrm{~mL})$, sodium diethyldithiocarbamate $(5 \% \mathrm{w} / \mathrm{v}, 15 \times 1.5 \mathrm{~mL})$, and DMF $(10$ $\times 1.5 \mathrm{~mL}$ ).

Lanthionine Cyclization. N,N-Diisopropylethylamine (10 equiv) was added to a solution of PyAOP ( 5 equiv) and HOAt ( 5 equiv) in DMF $(4 \mathrm{~mL})$. The solution was left to react for 1 min before addition to a microwave vial containing the resin. The vial was irradiated for 5 min at $60{ }^{\circ} \mathrm{C}$ before transfer of the resin back to the reaction syringe. The resin was then washed with DMF $(4 \times 1.5 \mathrm{~mL})$.

Cleavage from the Resin. Peptides were first washed with DMF $(4 \times 1.5 \mathrm{~mL}), \mathrm{CH}_{2} \mathrm{Cl}_{2}(4 \times 1.5 \mathrm{~mL})$, methanol $(4 \times 1.5 \mathrm{~mL})$, and diethyl ether $(4 \times 1.5 \mathrm{~mL})$ before drying in a desiccator for $45 \mathrm{~min}$. A solution of $94 \%$ TFA, $2.5 \%$ water, $2.5 \%$ EDT, and $1 \%$ TIPS $(2.5 \mathrm{~mL})$ was then added to the resin and left to agitate for $30 \mathrm{~min}$ on the platform shaker. After this time, the entire solution was transferred to a Falcon tube, and $12 \mathrm{~mL}$ of diethyl ether was added to precipitate the peptide. The cleavage procedure was then repeated with fresh cleavage solution $(2.5 \mathrm{~mL}$ containing $94 \% \mathrm{TFA}, 2.5 \%$ water, $2.5 \% \mathrm{EDT}$, and $1 \%$ TIPS) and left to agitate for a further $40 \mathrm{~min}$. The entire solution was again transferred to a Falcon tube before addition of $12 \mathrm{~mL}$ of diethyl ether to precipitate the peptide.

The Falcon tubes were then centrifuged for $10 \mathrm{~min}$ at $4000 \mathrm{rpm}$ and $4{ }^{\circ} \mathrm{C}$ before decanting off the diethyl ether solution. This process was performed three times in total before re-dissolving the peptide in water and lyophilizing.

HPLC Purification. The peptides were analyzed and purified via reverse phase HPLC using either a Varian ProStar system with a model 210 solvent delivery module and a model $320 \mathrm{UV}$ detector or a Dionex system with a PDA-100 photodiode array detector and a model ASI-100 automated sample injector. The preparative purification was performed using an ACE C8-300 semipreparative column $(150 \times 10 \mathrm{~mm}$, flow rate of $8.0 \mathrm{~mL} / \mathrm{min})$, with $\mathrm{UV}$ detection at 215 and $254 \mathrm{~nm}$, loaded with $200-1850 \mu \mathrm{L}$ aliquots of a $10-20$ $\mathrm{mg} / \mathrm{mL}$ solution of peptide dissolved in water. Gradient conditions are reported for each peptide. The fractions containing the correct peak were pooled, the solvent was removed under reduced pressure to approximately $2 \mathrm{~mL}$, and the solution was freeze-dried.

HPLC Analysis. All peptides were analyzed using UV detection at 215 and $254 \mathrm{~nm}$, using the conditions shown below. Retention times are reported for each peptide.

HPLC Method A. ACE C8-300 analytical column $(150 \times 10 \mathrm{~mm}$, flow rate of $1.0 \mathrm{~mL} / \mathrm{min}$ ). Gradient: $2-98 \%$ B over $20 \mathrm{~min}$ (A = water, $\mathrm{B}=$ acetonitrile, $0.1 \%$ TFA).

HPLC Method B. Dr Maisch C8 column (Reprosil Gold 200 C8, 5 $\mu \mathrm{m}, 250 \times 4.6 \mathrm{~mm}$, flow rate of $\left.1.0 \mathrm{~mL} \mathrm{~min}^{-1}\right)$. Gradient: $0-2 \mathrm{~min}$ on $95 \%$ A; then 5-95\% B over 48 min; then $95 \%$ B over 2 min; then $95-$ $5 \% \mathrm{~B}$ over $3 \mathrm{~min}$; then $5 \% \mathrm{~B}$ over $5 \mathrm{~min}(\mathrm{~A}=$ water, $\mathrm{B}=$ acetonitrile, $0.1 \%$ TFA).

ESI-MS Analysis. This was performed on a Waters Acquity Ultra Performance LC/MS machine using a linear gradient of 5-95\% B over $5 \min (\mathrm{A}=$ water, $\mathrm{B}=$ acetonitrile, $0.1 \% \mathrm{TFA})$. The analysis of the chromatograms was conducted using MassLynx software version 4.0.
Single Ring Thioether Analogue 2a. The synthesis was carried out on a $100 \mathrm{mg}$ scale using preloaded Fmoc-Lys(Boc)-NovaSyn resin (loading $0.24 \mathrm{mmol} / \mathrm{g}$ ). The following protected amino acids were used: Fmoc-Glu $\left(\mathrm{O}^{\mathrm{t}} \mathrm{Bu}\right)-\mathrm{OH}$; Fmoc-Gly-OH; Fmoc-Lys(Boc)-OH; Fmoc-Leu-OH; Fmoc-Met-OH: Fmoc-Arg(Pbf)-OH; Fmoc-Val-OH; Fmoc-Trp(Boc)-OH. The peptide was assembled following the strategy outlined in Scheme 1. Amino acid coupling steps, Fmoc deprotection, coupling of lanthionine 1, removal of the allyl/Aloc groups, and cyclization were all carried out according to the general procedures above. The peptide was cleaved under standard conditions, washed with ether, and lyophilized. The peptide was purified by semipreparative HPLC using a gradient of $5-50 \%$ B over $15 \mathrm{~min}(\mathrm{~A}=$ water, $\mathrm{B}=$ acetonitrile) to yield $3 \mathrm{mg}$ of product $(8 \%) . \mathrm{m} / z\left(\mathrm{ES}^{+}\right)$ $855.66\left([\mathrm{M}+2 \mathrm{H}]^{2+}\right), 570.68\left([\mathrm{M}+3 \mathrm{H}]^{3+}\right), 428.23\left([\mathrm{M}+4 \mathrm{H}]^{4+}\right)$. HPLC Method A: $t_{\mathrm{R}}=6.9 \mathrm{~min}$.

Single Ring Thioether Analogue 3a. The synthesis was carried out on a $100 \mathrm{mg}$ scale using preloaded Fmoc-Trp(Boc)-NovaSyn resin (loading $0.20 \mathrm{mmol} / \mathrm{g}$ ). The following protected amino acids were used: Fmoc-Glu $\left(\mathrm{O}^{\mathrm{t} B u}\right)-\mathrm{OH}$; Fmoc-Lys(Boc)-OH; Fmoc-Leu-OH; Fmoc-Met-OH: Fmoc-Arg(Pbf)-OH; Fmoc-Val-OH; Fmoc-Trp(Boc)-OH. The following Hmb-protected amino acids were also incorporated: Fmoc-(FmocHmb)-Gly-OH (position 5); Fmoc(FmocHmb)-Leu-OH (position 10); Fmoc-(FmocHmb)-Lys(Boc)$\mathrm{OH}$ (position 15). The peptide was assembled following the strategy outlined in Scheme 1. Amino acid coupling steps, Fmoc deprotection, coupling of lanthionine 1, removal of the allyl/Aloc groups, and cyclization were all carried out according to the general procedures above. The peptide was cleaved under standard conditions, washed with ether, and lyophilized. The peptide was purified by semipreparative HPLC using a gradient of $10-55 \%$ B over $8 \mathrm{~min}(\mathrm{~A}=$ water, $\mathrm{B}=$ acetonitrile) to yield $4 \mathrm{mg}$ of product $(9 \%) . \mathrm{m} / z\left(\mathrm{ES}^{+}\right)$ $538.27\left([\mathrm{M}+4 \mathrm{H}]^{4+}\right)$. HPLC Method A: $t_{\mathrm{R}}=2.4 \mathrm{~min}$.

Single Ring Thioether Analogue 4a. The synthesis was carried out on a $100 \mathrm{mg}$ scale using preloaded Fmoc-Trp(Boc)-NovaSyn resin (loading $0.20 \mathrm{mmol} / \mathrm{g}$ ). The following protected amino acids were used: Fmoc-Asp $\left(\mathrm{O}^{t} \mathrm{Bu}\right)-\mathrm{OH}$; Fmoc-Glu $\left(\mathrm{O}^{t} \mathrm{Bu}\right)-\mathrm{OH}$; Fmoc-Gly-OH; Fmoc-Lys(Boc)-OH; Fmoc-Leu-OH; Fmoc-Met-OH: Fmoc-Arg(Pbf)-OH; Fmoc-Ser $\left({ }^{\mathrm{t}} \mathrm{Bu}\right)-\mathrm{OH}$; Fmoc-Thr $\left({ }^{\mathrm{t}} \mathrm{Bu}\right)-\mathrm{OH}$; Fmoc-Val-OH; Fmoc-Trp(Boc)-OH. The peptide was assembled following the strategy outlined in Scheme 1. Amino acid coupling steps, Fmoc deprotection, coupling of lanthionine 1, removal of the allyl/Aloc groups, and cyclization were all carried out according to the general procedures above. The peptide was cleaved under standard conditions, washed with ether, and lyophilized. The peptide was purified by semipreparative HPLC using a gradient of $5-50 \%$ B over $15 \min (\mathrm{A}=$ water, $\mathrm{B}=$ acetonitrile $)$ to yield $0.5 \mathrm{mg}$ of product $(1 \%) . \mathrm{m} / z\left(\mathrm{ES}^{+}\right)$ $1021.71\left([\mathrm{M}+2 \mathrm{H}]^{2+}\right)$. HPLC Method A: $t_{\mathrm{R}}=2.6 \mathrm{~min}$.

Full-Length C-Terminal Thioether Analogue 12. The synthesis was carried out on a $100 \mathrm{mg}$ scale using preloaded Fmoc-Trp(Boc)NovaSyn resin (loading $0.20 \mathrm{mmol} / \mathrm{g}$ ). The following protected amino acids were used: Fmoc-Cys(Trt)-OH; Fmoc-Asp $\left(\mathrm{O}^{t} \mathrm{Bu}\right)-\mathrm{OH}$; Fmoc$\mathrm{Glu}\left(\mathrm{O}^{t} \mathrm{Bu}\right)-\mathrm{OH}$; Fmoc-Lys(Boc)-OH; Fmoc-Leu-OH; Fmoc-Met$\mathrm{OH}$ : Fmoc-Gln(Trt)-OH; Fmoc-Arg(Pbf)-OH; Fmoc-Ser $\left({ }^{\mathrm{t}} \mathrm{Bu}\right)-\mathrm{OH}$; Fmoc-Thr $\left({ }^{\mathrm{t}} \mathrm{Bu}\right)-\mathrm{OH}$; Fmoc-Val-OH; Fmoc-Trp(Boc)-OH; Fmoc$\operatorname{Tyr}\left({ }^{\mathrm{t}} \mathrm{Bu}\right)-\mathrm{OH}$. The following Hmb-protected amino acids were also incorporated: Fmoc-(FmocHmb)-Lys(Boc)-OH (positions 4, 14, 28); Fmoc-(FmocHmb)-Gly-OH (position 18); Fmoc-(FmocHmb)-Leu$\mathrm{OH}$ (position 23). The peptide was assembled following the strategy outlined in Scheme 2. Amino acid coupling steps, Fmoc deprotection, coupling of lanthionine 1, removal of the allyl/Aloc groups, and cyclization were all carried out according to the general procedures above. The peptide was cleaved from the resin using a solution of 96.5\% TFA, $2.5 \%$ water, and $1 \%$ TIPS $(2.5 \mathrm{~mL})$ and left to stir for $1 \mathrm{~h}$. After this time, the entire solution was transferred to a Falcon tube, and $12 \mathrm{~mL}$ of diethyl ether was added to precipitate the peptide. The Falcon tube was then centrifuged for $10 \mathrm{~min}$ at $4000 \mathrm{rpm}$ and $4{ }^{\circ} \mathrm{C}$ before decanting off the diethyl ether solution. This process was performed three times in total before re-dissolving the peptide in water and lyophilizing. The peptide was purified by semipreparative HPLC using a gradient of $10-55 \% \mathrm{~B}$ over $15 \mathrm{~min}$ ( $\mathrm{A}=$ water, $\mathrm{B}=$ 
acetonitrile, $0.1 \%$ TFA) to yield $0.3 \mathrm{mg}$ of product $(0.4 \%) . \mathrm{m} / z\left(\mathrm{ES}^{+}\right)$ $758.50\left([\mathrm{M}+5 \mathrm{H}]^{5+}\right)$. HPLC Method B: $t_{\mathrm{R}}=19.16 \mathrm{~min}$.

Full-Length Middle Ring Thioether Analogue 13. The synthesis was carried out on a $100 \mathrm{mg}$ scale using preloaded Fmoc$\operatorname{Trp}(\mathrm{Boc})-\mathrm{NovaSyn}$ resin (loading $0.20 \mathrm{mmol} / \mathrm{g}$ ). The following protected amino acids were used: Fmoc-Cys $(\mathrm{Trt})-\mathrm{OH}$ (positions 15, 25); Fmoc-Cys (S(Tmp))-OH (positions 2, 16); Fmoc-Asp $\left(\mathrm{O}^{t} \mathrm{Bu}\right)$ $\mathrm{OH}$; Fmoc-Glu $\left(\mathrm{O}^{t} \mathrm{Bu}\right)-\mathrm{OH}$; Fmoc-Lys(Boc)-OH; Fmoc-Leu-OH; Fmoc-Met-OH: Fmoc-Gln(Trt)-OH; Fmoc-Arg(Pbf)-OH; FmocSer $\left({ }^{\mathrm{t}} \mathrm{Bu}\right)-\mathrm{OH}$; Fmoc-Thr $\left({ }^{\mathrm{t}} \mathrm{Bu}\right)-\mathrm{OH}$; Fmoc-Val-OH; Fmoc-Trp(Boc)$\mathrm{OH}$; Fmoc- $\mathrm{Tyr}\left({ }^{\mathrm{t}} \mathrm{Bu}\right)-\mathrm{OH}$. The following Hmb-protected amino acids were also incorporated: Fmoc-(FmocHmb)-Lys(Boc)-OH (positions 4, 14, 28); Fmoc-(FmocHmb)-Gly-OH (position 18); Fmoc(FmocHmb)-Leu-OH (position 23). The peptide was assembled following the strategy outlined in Scheme 3. Amino acid coupling steps, Fmoc deprotection, coupling of lanthionine 1, removal of the allyl/Aloc groups, and cyclization were all carried out according to the general procedures above. Selective deprotection of the $S(\mathrm{Tmp})$ groups from the orthogonally protected cysteine residues was carried out using $5 \%$ DTT in $0.1 \mathrm{M}$ NMM in DMF $(1.5 \mathrm{~mL})(3 \times 30 \mathrm{~min})$ before washing with DMF $(4 \times 1.5 \mathrm{~mL})$. The deprotected cysteines were then cyclized using $\mathrm{N}$-chlorosuccinimide $(53.4 \mathrm{mg}, 2$ equiv) in DMF $(2 \mathrm{~mL})$ for $1.5 \mathrm{~h}$ before again washing with DMF $(4 \times 1.5 \mathrm{~mL})$. The peptide was cleaved from the resin using a solution of $96.5 \%$ TFA, $2.5 \%$ water, and $1 \%$ TIPS $(2.5 \mathrm{~mL})$ and left to stir for $1 \mathrm{~h}$. After this time, the entire solution was transferred to a Falcon tube, and $12 \mathrm{~mL}$ of diethyl ether was added to precipitate the peptide. The Falcon tube was then centrifuged for $10 \mathrm{~min}$ at $4000 \mathrm{rpm}$ and $4{ }^{\circ} \mathrm{C}$ before decanting off the diethyl ether solution. This process was performed three times in total before re-dissolving the peptide in water and lyophilizing. The peptide was purified by semipreparative HPLC using a gradient of $10-55 \% \mathrm{~B}$ over $15 \mathrm{~min}(\mathrm{~A}=$ water, $\mathrm{B}=$ acetonitrile, $0.1 \%$ TFA) to yield $5 \mathrm{mg}$ of product (7\%). This was then dissolved in water $(\mathrm{pH} 7.7)$ at $1 \mathrm{mg} / 10 \mathrm{~mL}$ concentration, stirred for a further 11 days at $4{ }^{\circ} \mathrm{C}$ to ensure complete disulfide bond formation, then lyophilized. $m / z\left(\mathrm{ES}^{+}\right) 544.64\left([\mathrm{M}+7 \mathrm{H}]^{7+}\right)$. HPLC Method B: $t_{\mathrm{R}}=19.15 \mathrm{~min}$.

Full-Length $\mathrm{N}$-Terminal Thioether Analogue 14. The synthesis was carried out on a $100 \mathrm{mg}$ scale using preloaded Fmoc-Trp(Boc)NovaSyn resin (loading $0.20 \mathrm{mmol} / \mathrm{g}$ ). The following protected amino acids were used: Fmoc-Cys(Trt)-OH; Fmoc-Asp $\left(\mathrm{O}^{t} \mathrm{Bu}\right)-\mathrm{OH}$; Fmoc$\mathrm{Glu}\left(\mathrm{O}^{t} \mathrm{Bu}\right)-\mathrm{OH}$; Fmoc-Lys(Boc)-OH; Fmoc-Leu-OH; Fmoc-Met$\mathrm{OH}$ : Fmoc-Gln(Trt)-OH; Fmoc-Arg(Pbf)-OH; Fmoc-Ser( $\left.{ }^{\mathrm{t}} \mathrm{Bu}\right)-\mathrm{OH}$; Fmoc-Thr $\left({ }^{\mathrm{t}} \mathrm{Bu}\right)-\mathrm{OH}$; Fmoc-Val-OH; Fmoc-Trp(Boc)-OH; Fmoc$\mathrm{Tyr}\left({ }^{\mathrm{t}} \mathrm{Bu}\right)-\mathrm{OH}$. The following Hmb-protected amino acids were also incorporated: Fmoc-(FmocHmb)-Lys(Boc)-OH (positions 4, 14, 28); Fmoc-(FmocHmb)-Gly-OH (position 18); Fmoc-(FmocHmb)-Leu$\mathrm{OH}$ (position 23). The peptide was assembled following the general strategy outlined in Scheme 2, but with the protected lanthionine 1 incorporated at position 16 and cyclized at position 2. Amino acid coupling steps, Fmoc deprotection, coupling of lanthionine 1, removal of the allyl/Aloc groups, and cyclization were all carried out according to the general procedures above. The peptide was cleaved from the resin using a solution of $96.5 \%$ TFA, $2.5 \%$ water, and $1 \%$ TIPS $(2.5$ $\mathrm{mL}$ ) and left to stir for $1 \mathrm{~h}$. After this time, the entire solution was transferred to a Falcon tube, and $12 \mathrm{~mL}$ of diethyl ether was added to precipitate the peptide. The Falcon tube was then centrifuged for 10 min at $4000 \mathrm{rpm}$ and $4{ }^{\circ} \mathrm{C}$ before decanting off the diethyl ether solution. This process was performed three times in total before redissolving the peptide in water and lyophilizing. The peptide was purified by semipreparative HPLC using a gradient of $10-55 \% \mathrm{~B}$ over $15 \mathrm{~min}(\mathrm{~A}=$ water, $\mathrm{B}=$ acetonitrile, $0.1 \% \mathrm{TFA})$ to yield $0.8 \mathrm{mg}$ of product $(1 \%) \cdot m / z\left(\mathrm{ES}^{+}\right) 544.64\left([\mathrm{M}+7 \mathrm{H}]^{7+}\right)$. HPLC Method B: $t_{\mathrm{R}}$ $=19.11 \mathrm{~min}$.

Synthesis of ProTx-II. The synthesis was carried out on a $100 \mathrm{mg}$ scale using preloaded Fmoc-Trp(Boc)-NovaSyn resin (loading 0.20 $\mathrm{mmol} / \mathrm{g}$ ). The following protected amino acids were used: FmocCys(Trt)-OH, Fmoc-Asp $\left(\mathrm{O}^{t} \mathrm{Bu}\right)-\mathrm{OH}$; Fmoc-Glu $\left(\mathrm{O}^{\mathrm{t}} \mathrm{Bu}\right)-\mathrm{OH}$; FmocGly-OH; Fmoc-Lys(Boc)-OH; Fmoc-Leu-OH; Fmoc-Met-OH: Fmoc-Gln(Trt)-OH; Fmoc-Arg (Pbf)-OH; Fmoc-Ser $\left({ }^{\mathrm{t}} \mathrm{Bu}\right)-\mathrm{OH}$; Fmoc-Thr $\left({ }^{\mathrm{t}} \mathrm{Bu}\right)-\mathrm{OH}$; Fmoc-Val-OH; Fmoc-Trp(Boc)-OH; Fmoc-
$\operatorname{Tyr}\left({ }^{\mathrm{t}} \mathrm{Bu}\right)-\mathrm{OH}$. Amino acid coupling steps and Fmoc deprotection were all carried out according to the general procedures above. The peptide was cleaved under standard conditions, washed with ether, and lyophilized.

ProTx-II/7d. The crude peptide was purified using a gradient of $35-60 \% \mathrm{~B}$ over $15 \min (\mathrm{A}=$ water, $\mathrm{B}=$ acetonitrile, $0.1 \% \mathrm{TFA})$ to give the linear peptide: $m / z\left(\mathrm{ES}^{+}\right) 765.93\left([\mathrm{M}+5 \mathrm{H}]^{5+}\right), 639.57([\mathrm{M}$ $+6 \mathrm{H}]^{6+}$. Analytical HPLC: $t_{\mathrm{R}}=2.4 \mathrm{~min}$. The peptide was then allowed to cyclize for 7 days in pure water at $4{ }^{\circ} \mathrm{C}$ and a concentration of 0.1 $\mathrm{mg} / \mathrm{mL}$. The solution was then concentrated to approximately $2 \mathrm{~mL}$, flash frozen, and lyophilized to yield the cyclized peptide as a white solid $(10 \mathrm{mg}, 13 \%) \mathrm{m} / z\left(\mathrm{ES}^{+}\right)$1276.51 $\left([\mathrm{M}+3 \mathrm{H}]^{3+}\right)$, $957.43([\mathrm{M}+$ $\left.4 \mathrm{H}]^{4+}\right), 765.93\left([\mathrm{M}+5 \mathrm{H}]^{5+}\right), 638.72\left([\mathrm{M}+6 \mathrm{H}]^{6+}\right)$. HPLC Method B: $t_{\mathrm{R}}=21.80 \mathrm{~min}$.

ProTx-II/24h. Glutathione $(0.15 \mathrm{mM})$ and glutathione disulfide $(0.3 \mathrm{mM})$ were added to a mixture of urea $(2 \mathrm{M})$ and Tris- $\mathrm{HCl}(0.1$ $\mathrm{M})$ in water. The $\mathrm{pH}$ was adjusted to 8.0 using saturated aqueous sodium bicarbonate. A solution of crude linear ProTx-II was added at a concentration of $0.1 \mathrm{mg} / \mathrm{mL}$ and left to stir for $24 \mathrm{~h}$ at room temperature. After this time, the $\mathrm{pH}$ of the solution was adjusted to $\mathrm{pH} 3$ using $\mathrm{HCl}(2 \mathrm{M})$. The peptide was purified by semipreparative HPLC: gradient: $0-1.5 \mathrm{~min}$ on $95 \% \mathrm{~A}$; then $5-70 \% \mathrm{~B}$ over $38 \mathrm{~min}$; then $70 \%$ B over $2.0 \mathrm{~min}$; then $70-5 \%$ B over $1.1 \mathrm{~min}$; then $5 \% \mathrm{~B}$ over $2.4 \min (\mathrm{A}=$ water, $\mathrm{B}=$ acetonitrile, $0.1 \% \mathrm{TFA})$. The peptide was further purified using analytical HPLC Method B: $t_{R}=21.03 \mathrm{~min}$.

Automated and Manual Patch Clamp Assays. Peptides were diluted to a concentration of $100 \mathrm{nM}$ and tested against stably transfected cell lines expressing the $\mathrm{hNa}_{\mathrm{v}} 1.7$ receptor. Peptides $\mathbf{2 a}, \mathbf{2} \mathbf{b}$, 4a, 4b, 5b, 12, 13, 14, ProTx-II/7d, Sigma, and Smartox were tested against stably transfected cell lines expressing the $\mathrm{hNa}_{\mathrm{v}} 1.7$ receptor, using the hNav1.7-HEK cell IonWorks Population Patch Clamp Assay, as designed by Essen Bioscience. These peptides were tested at 11 different points to make an IC50 curve using 3-fold dilution from 1 $\mu \mathrm{M}$ to $0.000001 \mu \mathrm{M}$ in triplicate, using tetracaine as the control molecule. The samples were allowed to incubate for 5-7 min before testing occurred and were tested in the presence of $0.1 \%$ bovine serum albumin to prevent the samples adhering to the side of the microtiter plate. The percentage inhibition between the first and 20th pulses was then analyzed and plotted on a graph. Peptides 3a, 3b, 14, ProTx-II/ 24h, ProTx-II/7d, Sigma, Smartox, and the linear sequence of ProTxII were tested using the QPatch Patch Clamp Assay as designed by B'SYS GmbH. $\mathrm{hNa}_{\mathrm{v}} 1.7$ inward peak currents were recorded in $\mathrm{CHO}$ cells stably transfected with cDNA encoding this sodium channel in the resting, fast and slow inactivated state. Lidocaine was used as the reference. Full details of these experiments are in the Supporting Information.

HPLC Analysis of ProTx-II Samples. ProTx-II samples were mixed as indicated and co-injected into a Dr Maisch C8 column, eluting with HPLC Method B.

NanoESI and IM-MS Analyses. All measurements were carried out using a G2Si mass spectrometer (Waters, UK). The TOF analyzer was operated in $\mathrm{V}$-optic mode and tuned for an operating resolution of $20000 \mathrm{fwhm}$. The instrument was mass calibrated using a $2 \mathrm{mg} / \mathrm{mL}$ solution of CsI. ProTx-II samples were dissolved in $50 \% \mathrm{MeOH}$ with $0.1 \% \mathrm{HCOOH}$ and $2.5 \mu \mathrm{L}$ aliquots, of $10 \mu \mathrm{M}$ concentration, were delivered to the mass spectrometer by means of nanoESI using goldcoated capillaries, prepared in house. Instrumental parameters were as follows unless otherwise specified: capillary voltage $0.9 \mathrm{kV}$, cone voltage $40 \mathrm{~V}$, trap energy $4 \mathrm{~V}$, transfer energy $2 \mathrm{~V}$, bias voltage $45 \mathrm{~V}$, IMS pressure $3 \mathrm{mbar}$, IMS wave velocity $650 \mathrm{~m} / \mathrm{s}$, IMS wave height 35 V. Data acquisition, processing, and calculation of theoretical isotopic distributions were carried out using MassLynx (v4.1) software (Waters Corp., Milford, MA). IM-MS data were processed in Driftscope v2.8 and exported for further analysis to MassLynx.

\section{ASSOCIATED CONTENT}

\section{Supporting Information}

The Supporting Information is available free of charge on the ACS Publications website at DOI: $10.1021 /$ jacs.7b06506. The 
X-ray crystal structure of ProTx-II has been deposited in the Protein Data Bank with accession code 500U.

X-ray crystallographic data for ProTx-II (CIF)

Experimental procedures for the multigram-scale synthesis of protected lanthionine $\mathbf{1}$ and for the synthesis of peptides $\mathbf{2 b}, \mathbf{3 b}, \mathbf{4 b}$, and $\mathbf{5 b} ;{ }^{1} \mathrm{H}$ NMR spectra for key synthetic intermediates and for $\mathbf{1}$; mass spectral and HPLC data for all peptides after purification; crystallization and diffraction methods for ProTx-II; complete materials and methods, and full data from the patch clamp assays (PDF)

\section{AUTHOR INFORMATION}

\section{Corresponding Authors}

*k.thalassinos@ucl.ac.uk

*a.b.tabor@ucl.ac.uk

\section{ORCID}

Alethea B. Tabor: 0000-0001-8216-0347

\section{Notes}

The authors declare no competing financial interest.

\section{ACKNOWLEDGMENTS}

We thank Eisai for a Ph.D. studentship (to Z.V.F.W.), the Wellcome Trust for a studentship (to S.M., 109073/Z/15/Z), the EPSRC for a studentship (to R.D.), and BBSRC/Waters for a CASE studentship (to A.C.). The G2Si ion mobility mass spectrometer was purchased with a grant from the Wellcome Trust (104913/Z/14/ZBM). Diffraction data were collected at the Berkeley Center for Structural Biology (Berkeley, CA). The Berkeley Center for Structural Biology is supported in part by the National Institutes of Health, National Institute of General Medical Sciences, and the Howard Hughes Medical Institute. The Advanced Light Source is supported by the Director, Office of Science, Office of Basic Energy Sciences, of the U.S. Department of Energy under Contract No. DE-AC0205CH11231. The Gonen laboratory is supported by the Howard Hughes Medical Institute. We also thank Dr. Carolyn Hyde (Bio-Analysis Centre, London Bioscience Innovation Centre), Dr. Ian Kilford (Eisai), Prof. Rob Liskamp and Dr. Helmus Van De Langemheen (Department of Chemistry, University of Glasgow), Dr. Abil Aliev, Dr. Jamie Baker and Prof. Erik Årstad (Department of Chemistry, UCL), Dr. Srinivasan Kanumilli, Dr. Tim Dale, and Dr. Derek Trezise (Essen Biosciences), and Dr. Daniel Konrad and Dr. Alexandra Illy (B’SYS GmbH) for numerous helpful discussions.

\section{REFERENCES}

(1) Fosgerau, K.; Hoffmann, T. Drug Discovery Today 2015, 20, 122.

(2) King, G. F. Venoms to drugs: venom as a source for the development of human therapeutics; Royal Society of Chemistry: Cambridge, 2015.

(3) Pope, J. E.; Deer, T. R. Expert Opin. Pharmacother. 2013, 14, 957.

(4) King, G. F.; Vetter, I. ACS Chem. Neurosci. 2014, 5, 749.

(5) Harvey, A. L. Toxicon 2014, 92, 193.

(6) Armishaw, C. J.; Daly, N. L.; Nevin, S. T.; Adams, D. J.; Craik, D. J.; Alewood, P. F. J. Biol. Chem. 2006, 281, 14136.

(7) Muttenthaler, M.; Nevin, S. T.; Grishin, A. A.; Ngo, S. T.; Choy, P. T.; Daly, N. L.; Hu, S.-H.; Armishaw, C. J.; Wang, C.-I. A.; Lewis, R. J.; Martin, J. L.; Noakes, P. G.; Craik, D. J.; Adams, D. J.; Alewood, P. F. J. Am. Chem. Soc. 2010, 132, 3514.

(8) MacRaild, C. A.; Illesinghe, J.; van Lierop, B. J.; Townsend, A. L.; Chebib, M.; Livett, B. G.; Robinson, A. J.; Norton, R. S. J. Med. Chem. 2009, 52, 755 .
(9) Van Lierop, B. J.; Robinson, S. D.; Kompella, S. N.; Belgi, A.; McArthur, J. R.; Hung, A.; MacRaild, C. A.; Adams, D. J.; Norton, R. S.; Robinson, A. J. ACS Chem. Biol. 2014, 8, 1815.

(10) Guo, Y.; Sun, D.-M.; Wang, F.-L.; He, Y.; Liu, L.; Tian, C.-L. Angew. Chem., Int. Ed. 2015, 54, 14276.

(11) Gleeson, E. C.; Jackson, W. R.; Robinson, A. J. Tetrahedron Lett. 2016, 57, 4325 .

(12) Hargittai, B.; Solé, N. A.; Groebe, D. R.; Abramson, S. N.; Barany, G. J. Med. Chem. 2000, 43, 4787-4792.

(13) Dekan, Z.; Vetter, I.; Daly, D. L.; Craik, D. J.; Lewis, R. J.; Alewood, P. F. J. Am. Chem. Soc. 2011, 133, 15866.

(14) Stymiest, J. L.; Mitchell, B. F.; Wong, S.; Vederas, J. C. J. Org. Chem. 2005, 70, 7799.

(15) Derksen, D. J.; Stymiest, J. L.; Vederas, J. C. J. Am. Chem. Soc. 2006, 128, 14252.

(16) Knerr, P. J.; Tzekou, A.; Ricklin, D.; Qu, H. C.; Chen, H.; van der Donk, W. A.; Lambris, J. D. ACS Chem. Biol. 2011, 6, 753.

(17) Guo, Y.; Liu, C.; Song, H.; Wang, F.-L.; Zou, Y.; Wu, Q.-Y.; Hu, H.-G. RSC Adv. 2017, 7, 2110.

(18) Polinsky, A.; Cooney, M. G.; Toy-Palmer, A.; Ösapay, G.; Goodman, M. J. Med. Chem. 1992, 35, 4185.

(19) Ösapay, G.; Prokai, L.; Kim, H.-S.; Medzihradszky, K. F.; Coy, D. H.; Liapakis, G.; Reisine, T.; Melacini, G.; Zhu, Q.; Wang, S. H.-H.; Mattern, R.-H.; Goodman, M. J. Med. Chem. 1997, 40, 2241.

(20) Dantas de Araujo, A.; Mobli, M.; Castro, J.; Harrington, A. M.; Vetter, I.; Dekan, Z.; Muttenthaler, M.; Wan, J.-J.; Lewis, R. J.; King, G. F.; Brierley, S. M.; Alewood, P. F. Nat. Commun. 2014, 5, 3165.

(21) Bregant, S.; Tabor, A. B. J. Org. Chem. 2005, 70, 2430.

(22) Tabor, A. B. Org. Biomol. Chem. 2011, 9, 7606.

(23) Tabor, A. B. Bioorg. Chem. 2014, 55, 39.

(24) Ross, A. C.; Liu, H.; Pattabiraman, V. R.; Vederas, J. C. J. Am. Chem. Soc. 2010, 132, 462.

(25) Liu, W.; Chan, A. S. H.; Liu, H.; Cochrane, S. A.; Vederas, J. C. J. Am. Chem. Soc. 2011, 133, 14216.

(26) Middleton, R. E.; Warren, V. A.; Kraus, R. L.; Hwang, J. C.; Liu, C. J.; Dai, G.; Brochu, R. M.; Kohler, M. G.; Gao, Y.-D.; Garsky, V. M.; Bogusky, M. J.; Mehl, J. T.; Cohen, C. J.; Smith, M. M. Biochemistry 2002, 41, 14734.

(27) Xiao, Y.; Bingham, J.-P.; Zhu, W.; Moczydlowski, E.; Liang, S.; Cummins, T. R. J. Biol. Chem. 2008, 283, 27300.

(28) Murray, J. K.; Ligutti, J.; Liu, D.; Zou, A.; Poppe, L.; Li, H.; Andrews, K. L.; Moyer, B. D.; McDonough, S. I.; Favreau, P.; Stöcklin, R.; Miranda, L. P. J. Med. Chem. 2015, 58, 2299.

(29) Shcherbatko, A.; Rossi, A.; Foletti, D.; Zhu, G.; Bogin, O.; Casas, M. G.; Rickert, M.; Hasa-Moreno, A.; Bartsevich, V.; Crameri, A.; Steiner, A. R.; Henningsen, R.; Gill, A.; Pons, J.; Shelton, D. L.; Rajpal, A.; Strop, P. J. Biol. Chem. 2016, 291, 13974.

(30) Akondi, K. B.; Muttenthaler, M.; Dutertre, S.; Kaas, Q.; Craik, D. J.; Lewis, R. J.; Alewood, P. F. Chem. Rev. 2014, 114, 5815.

(31) Ferrat, G.; Darbon, H. Toxin Rev. 2005, 24, 361.

(32) Schmalhofer, W. A.; Calhoun, J.; Burrows, R.; Bailey, T.; Kohler, M. G.; Weinglass, A. B.; Kaczorowski, G. J.; Garcia, M. L.; Koltzenburg, M.; Priest, B. T. Mol. Pharmacol. 2008, 74, 1476.

(33) Cox, J. J.; Reimann, F.; Nicholas, A. K.; Thornton, G.; Roberts, E.; Springell, K.; Karbani, G.; Jafri, H.; Mannan, J.; Raashid, Y.; AlGazali, L.; Hamamy, H.; Valente, E. M.; Gorman, S.; Williams, R.; McHale, D. P.; Wood, J. N.; Gribble, F. M.; Woods, C. G. Nature 2006, 444, 894

(34) Yang, Y.; Wang, Y.; Li, S.; Xu, Z.; Li, H.; Ma, L.; Fan, J.; Bu, D.; Liu, B.; Fan, Z.; Wu, G.; Jin, J.; Ding, B.; Zhu, X.; Shen, Y. J. Med. Genet. 2004, 41, 171.

(35) Henriques, S. T.; Deplazes, E.; Lawrence, N.; Cheneval, O.; Chaousis, S.; Inserra, M.; Thongyoo, P.; King, G.; Mark, A. E.; Vetter, I.; Craik, D. J.; Schroeder, C. I. J. Biol. Chem. 2016, 291, 17049.

(36) Park, J. H.; Carlin, K. P.; Wu, G.; Ilyin, V. I.; Musza, L. L.; Blake, P. R.; Kyle, D. J. J. Med. Chem. 2014, 57, 6623.

(37) Smith, J. J.; Cummins, T. R.; Alphy, S.; Blumenthal, K. M. J. Biol. Chem. 2007, 282, 12687. 
(38) Xiao, Y.; Blumenthal, K.; Jackson, J. O.; Liang, S.; Cummins, T. R. Mol. Pharmacol. 2010, 78, 1124.

(39) Flinspach, M.; Xu, Q.; Piekarz, A. D.; Fellows, R.; Hagan, R.; Gibbs, A.; Liu, Y.; Neff, R. A.; Freedman, J.; Eckert, W. A.; Zhou, M.; Bonesteel, R.; Pennington, M. W.; Eddinger, K. A.; Yaksh, T. L.; Hunter, M.; Swanson, R. V.; Wickenden, A. D. Sci. Rep. 2017, 7, 39662.

(40) Deuis, J. R.; Dekan, Z.; Wingerd, J. S.; Smith, J. J.; Munasinghe, N. R.; Bhola, R. F.; Imlach, W. L.; Herzig, V.; Armstrong, D. A.; Rosengren, K. J.; Bosmans, F.; Waxman, S. G.; Dib-Hajj, S. D.; Escoubas, P.; Minett, M. S.; Christie, M. J.; King, G. F.; Alewood, P. F.; Lewis, R. J.; Wood, J. N.; Vetter, I. Sci. Rep. 2017, 7, 40883.

(41) Pedersen, S. L.; Tofteng, A. P.; Malik, L.; Jensen, K. J. Chem. Soc. Rev. 2012, 41, 1826.

(42) Machauer, R.; Waldmann, H. Chem. - Eur. J. 2001, 7, 2933.

(43) Mothia, B.; Appleyard, A. N.; Wadman, S.; Tabor, A. B. Org. Lett. 2011, 13, 4216.

(44) Albericio, F.; Cases, M.; Alsina, J.; Triolo, S. A.; Carpino, L. A.; Kates, S. A. Tetrahedron Lett. 1997, 38, 4853.

(45) Wilson-Stanford, S.; Kalli, A.; Håkansson, K.; Kastrantas, J.; Orugunty, R. S.; Smith, L. Appl. Environ. Microbiol. 2009, 75, 1381.

(46) Johnson, T.; Quibell, M.; Sheppard, R. C. J. Pept. Sci. 1995, 1, 11.

(47) Postma, T. M.; Albericio, F. Org. Lett. 2013, 15, 616.

(48) Park, J. H.; Carlin, K. P.; Wu, G.; Ilyin, V. I.; Kyle, D. J. J. Pept. Sci. 2012, 18, 442.

(49) Annis, I.; Hargittai, B.; Barany, G. Methods Enzymol. 1997, 289, 198.

(50) Steiner, A. M.; Bulaj, G. J. Pept. Sci. 2011, 17, 1.

(51) Khoo, K. K.; Gupta, K.; Green, B. R.; Zhang, M.-M.; Watkins, M.; Olivera, B. M.; Balaram, P.; Yoshikami, D.; Bulaj, G.; Norton, R. S. Biochemistry 2012, 51, 9826.

(52) Shu, Q.; Lu, S.-H.; Gu, X.-C.; Liang, S.-P. Protein Sci. 2002, 11, 245.

(53) Thalassinos, K.; Grabenauer, M.; Slade, S. E.; Hilton, G. R.; Bowers, M. T.; Scrivens, J. H. Anal. Chem. 2009, 81, 248.

(54) Santos, L. F.; Iglesias, A. H.; Pilau, E. J.; Gomes, A. F.; Gozzo, F. C. J. Am. Soc. Mass Spectrom. 2010, 21, 2062.

(55) Scarff, C. A.; Thalassinos, K.; Hilton, G. R.; Scrivens, J. H. Rapid Commun. Mass Spectrom. 2008, 22, 3297.

(56) Murray, J. K.; Ligutti, J.; Liu, D.; Zou, A.; Poppe, L.; Li, H.; Andrews, K. L.; Moyer, B. D.; McDonough, S. I.; Favreau, P.; Stöcklin, R.; Miranda, L. P. J. Med. Chem. 2015, 58, 2299.

(57) Pulka-Ziach, K.; Pavet, V.; Chekkat, N.; Estieu-Gionnet; Rohac, R.; Lechner, M.-C.; Smulski, C.; Zeder-Lutz, G.; Altschuh, D.; Gronemeyer, H.; Fournel, S.; Odaert, B.; Guichard, G. ChemBioChem 2015, 16, 293.

(58) Upert, G.; Mourier, G.; Pastor, A.; Verdenaud, M.; Alili, D.; Servent, D.; Gilles, N. Chem. Commun. 2014, 50, 8408.

(59) Salamanca, S.; Chang, J.-Y. Protein J. 2006, 25, 275.

(60) Chang, J.-Y.; Li, L. Arch. Biochem. Biophys. 2005, 437, 85.

(61) Lajoie, D. M.; Roberts, S. A.; Zobel-Thropp, P. A.; Delahaye, J. L.; Bandarian, V.; Binford, G. J.; Cordes, M. H. J. J. Biol. Chem. 2015, 290, 10994. 